Chapter 5

\title{
The Use of New Technologies in Dyeing of Proteinous Fibers
}

\author{
Riza Atav \\ Additional information is available at the end of the chapter \\ http://dx.doi.org/10.5772/53912
}

\section{Introduction}

Wool consists principally of one member of a group of proteins called keratins; other members of this group include the proteins of hair, feathers, beaks, claws, hooves, horn and even certain types of skin tumour [1]. The main substance of wool is a keratin. Keratin macromolecules are crosslinked with cystine residues and contain a variety of side chains, some basic and some acidic [2]. Wool fibers consist of cortical cells and cuticular cells, which are located in the outermost part of the fiber surrounding the cortical cells. They consist of endocuticle, $\mathrm{A}$ and B exocuticle, and an exterior hydrophobic thin membrane called the epicuticle [3]. Both layers have a tremendous influence on dyeing because of their hydrophobic characteristics. The cuticle is separated from the underlying cortex by the intercellular material, which is called the cell membrane complex (CMC) and consists of non-keratinous proteins and lipids [2].

The morphology of the wool fiber surface plays an important role in textile finishing processes. The covalently bound fatty acids and the high amount of disulphide bridges make the outer wool surface highly hydrophobic. Especially in the printing and dyeing of wool, the hydrophobic character of the wool surface is disturbing. Diffusion of the hydrophilic dyes at and into the fibers is hindered. For this reason, the hydrophilicity and dyeability properties of the wool fiber should be developed [4]. Wool dyeing is a degradative process involving high temperature for long periods in acidic to neutral $\mathrm{pH}$ medium to achieve good penetration, optimum fastness, and dye uptake. The results can be harsh handle, discomfort, and a deterioration of properties that impact consumer wear, care, and aesthetic appreciation [5].

Silk fiber is protein fiber that is produced from silk worms [6]. Silk has been called "the queen of fibers", its natural luster, handle and draping properties being superior to those of many other textile fibers [7]. It is composed of different alpha amino acids orienting to form 
long chain polymer by condensation and polymerization. Silk fiber consists of $97 \%$ protein and the others are wax, carbohydrate, pigments, and inorganic compounds. The proteins in silk fiber are $75 \%$ fibroin and $25 \%$ sericin by weight, approximately. The sericin makes silk fiber to be strong and lackluster; therefore, it must be degummed before dyeing [6]. Silk fibroin, like wool keratin, is formed by the condensation of $\alpha$-amino acids into polypeptide chains, but the long-chain molecules of silk fibroin are not linked together by disulfide bridges as they are in wool. Chemical treatments can cause modification of main peptide chains, and side chains of amino acids, which in turn influence the fiber's chemical, physical, and mechanical properties [8]. Silk fiber is easily damaged when dyeing at the boil, so lowtemperature dyeing is usualy preferred [7]. Because the brilliancy of dyed and printed silk fabrics is a decisive factor for evaluating the quality of silk fabrics, dyeability of silk fibers is one of the most attractive topics for applied and basic research [9].

In recent years, many attempts have been made to improve various aspects of dyeing, and new technologies have been, and are being developed to reduce fiber damage, decrease energy consumption and increase productivity [10]. In this chapter, new technologies that improve the dyeability of proteinous fibers such as ultrasound, ultraviolet, ozone, plasma, gamma irradiation, laser, microwave, e-beam irradiation, ion implantation, and supercritical carbondioxide will be overviewed.

\section{Ultrasound technology}

Sound is transmitted through a medium by inducing vibrational motion of the molecules through which it is traveling. This vibrational motion represents the sound frequency [11]. Ultrasound is sound of a frequency that is above the threshold of human hearing [12]. The lowest audible frequency for humans is about $18 \mathrm{~Hz}$ and the highest is normally around $18-20 \mathrm{kHz}$ for adults, above which it becomes inaudible and is defined as ultrasound [11]. In recent decades the use of ultrasound technology has established an important place in different industrial processes such as the medical field, and has started to revolutionize environmental protection. The idea of using ultrasound in textile wet processes is not a new one. On the contrary there are many reports from the 1950s and 1960s describing the beneficial effects of ultrasound in textile wet processes. In spite of encouraging results from laboratory-scale studies, the ultrasound-assisted wet textile processes have not been implemented on an industrial scale as yet [13].

In practice, three ranges of frequencies (Fig. 1) are reported for three distinct uses of ultrasound: low frequency or conventional power ultrasound (20-100 kHz), medium frequency ultrasound and diagnostic or high frequency ultrasound (2-10 MHz) [13].

As the sound wave passes through water in the form of compression and rarefaction cycles, the average distance between the water molecules varies. If the pressure amplitude of the sound is sufficiently large, then the distance between the adjacent molecules can exceed the critical molecular distance during the rarefaction cycle. At that moment a new liquid surface is created in the form of voids. This phenomenon is called acoustic cavitation [15]. 


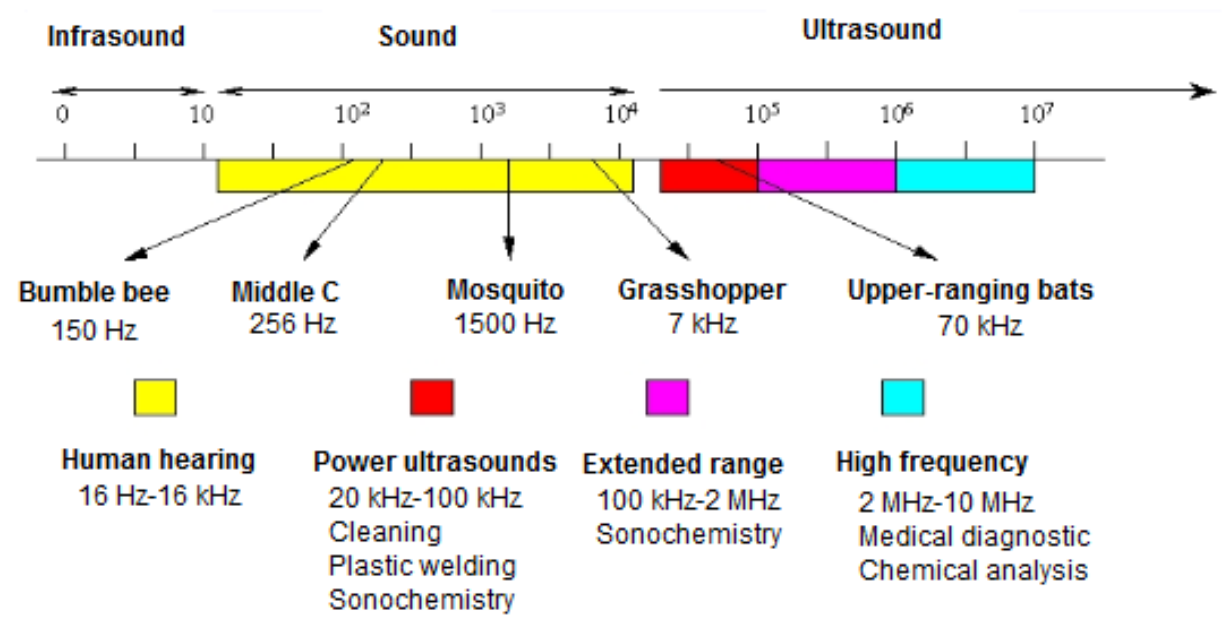

Figure 1. Classification of sound according to the frequency [14]

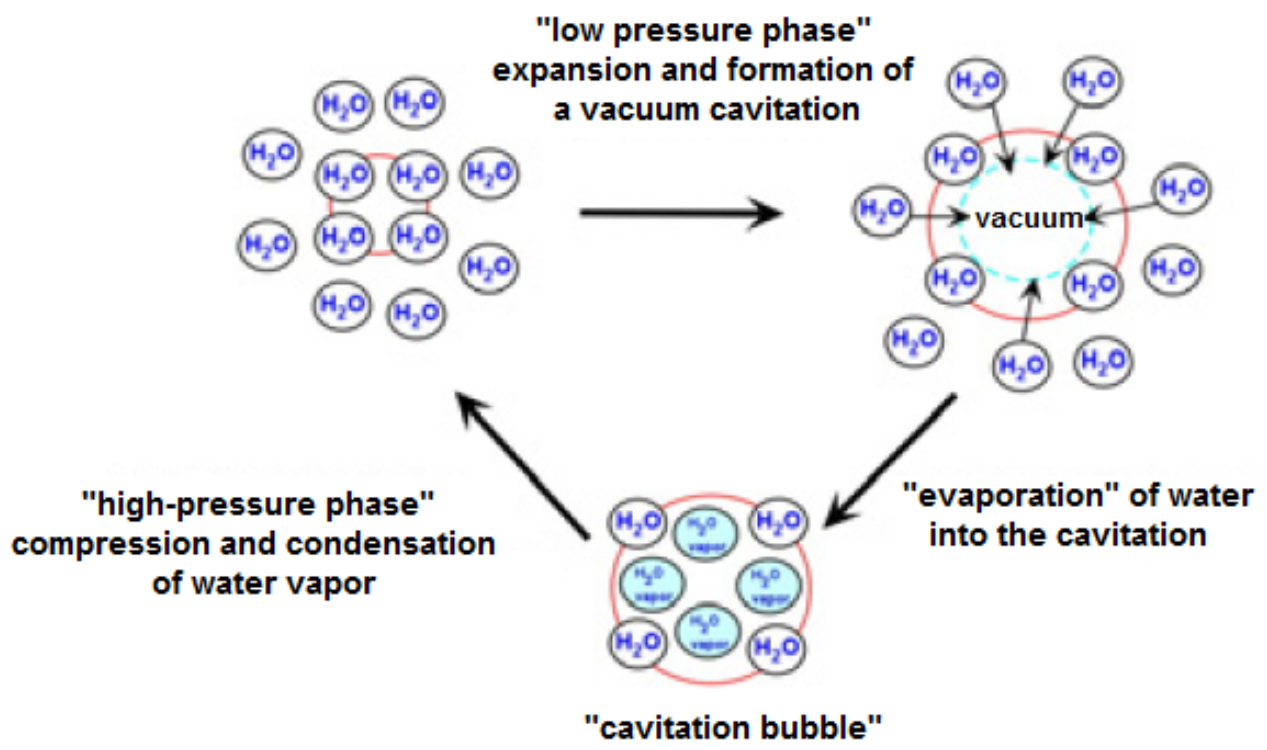

Figure 2. Formation of a cavitation buble [16]

Power ultrasound can enhance a wide variety of chemical and physical processes, mainly due to the phenomenon known as cavitation in a liquid medium that is the growth and ex- 
plosive collapse of microscopic bubbles. Sudden and explosive collapse of these bubbles can generate "hot spots", i.e., localized high temperature, high pressure, shock waves and severe shear force capable of breaking chemical bonds [17]. High temperature and pressures resulting from the collapse of the transient cavitation bubbles are responsible for all the observed effects of ultrasound [18]. Parameters which affect cavitation and bubble collapse are:

- Properties of the solvent: The solvent used to perform sample treatment with ultrasonication must be carefully chosen. As a general rule, most applications are performed in water. However, other less polar liquids, such as some organics, can be also used, depending on the intended purpose [19]. Cavities are more readily formed when using a solvent with high vapor pressure, low viscosity and low surface tension. But at high vapor pressure more vapor enters the cavitation bubble during its formation and the bubble collapse is cushioned and less violent [13].

- Properties of gases: Soluble gases should result in the formation of a larger number of cavitation nuclei, but the greater the solubility of the gas is the more gas molecules should penetrate the cavity. Therefore, a less violent and intense shock wave is created on bubble collapse [13].

- External pressure: With increasing external pressure, the vapor pressure of the liquid decreases and higher intensity is necessary to induce cavitation [13]. In addition, there is an increment in the intensity of the cavitational bubble collapse and, consequently, an enhancement in sonochemical effects is obtained. For a specific frequency there is a particular external pressure that will provide an optimum sonochemical reaction [19].

- External temperature: Higher external temperature reduces the intensity necessary to induce cavitation due to the increased vapor pressure of the liquid. At higher external temperatures more vapor diffuses into the cavity, and the cavity collapse is cushioned and less violent [13].

- Frequency of the sound wave: At high sonic frequencies, on the order of the MHz, the production of cavitation bubbles becomes more difficult than at low sonic frequencies, of the order of the $\mathrm{kHz}$. To achieve cavitation, as the sonic frequency increases, so the intensity of the applied sound must be increased, to ensure that the cohesive forces of the liquid media are overcome and voids are created [19]. Lower frequency produces more violent cavitation and, as a consequence, higher localized temperatures and pressures. At very high frequency, the expansion part of the sound wave is too short to permit molecules to be pulled apart sufficiently to generate a bubble [13].

Cavitation induced by ultrasound will allow accelerating processes and obtaining the same results as existing techniques but with a lower temperature and low dye and chemical concentrations [20]. For this reason textile wet processes assisted by ultrasound are of high interest for the textile industry. A review of earlier studies using ultrasound in textile wet processes was compiled by Thakore et al. Ultrasound-assisted textile dyeing was first reported by Sokolov and Tumansky in 1941 [13]. Some of the benefits of using of ultrasonics in dyeing can be listed as below; 
- energy savings by dyeing at lower temperatures and reduced processing times,

- environmental improvements by reduced consumption of auxiliary chemicals,

- lower overall processing costs (due to less energy and chemical consumption), thereby increasing industry competitiveness [21]

Improvements observed in ultrasound-assisted dyeing processes are generally attributed to 3 main phenomenons,

- Dispersion: breaking up of micelles and high molecular weight aggregates into uniform dispersions in the dye bath,

- Degassing: expulsion of dissolved or entrapped gas or air molecules from fiber into liquid and removal by cavitation, thus facilitating dye-fiber contact, and

- Diffusion: accelerating the rate of dye diffusion inside the fiber by piercing the insulating layer covering the fiber and accelerating the interaction or chemical reaction, if any, between dye and fiber [11].

A good wool dyeing process must provide a satisfactory uptake of dye bath and an adequate penetration of dye into the fiber, with the practical advantages of good wet fastness and uniform coloration. The conventional methods for wool dyeing are based on long times at temperature close to the boiling point, in order to ensure good results of dye penetration and leveling. These conditions can damage the fibers, with negative effects on the characteristics of the finished material. Such damage can be minimized by reducing the operation time or, better yet, by reducing the dyeing temperature. Recently, ultrasound assisted wool dyeing was studied with the aim to reduce temperature or dyeing time with respect to the conventional dyeing technique [22]. Some literature related to the use of ultrasound technology in dyeing of proteinous fibers is summarized below.

Shukla and Mathur (1995) studied the dyeing process of silk using cationic, acid and metalcomplex dyes at low temperatures, assisted by a low frequency ultrasound of $26 \mathrm{kHz}$ and compared the results of dye uptake with those obtained by conventional processes. Their results show that silk dyeing in the presence of ultrasound increases the dye uptake for all classes of dyes at lower dyeing temperatures $\left(45^{\circ} \mathrm{C}\right.$ and $\left.50^{\circ} \mathrm{C}\right)$ and a shorter dyeing time (15 min.), as compared with conventional dyeing at $85^{\circ} \mathrm{C}$ for $60 \mathrm{~min}$. Furthermore, there was no apparent fiber damage caused by cavitation [23].

Kamel et al. (2005) have investigated the dyeing of wool fabrics with lac as a natural dye in both conventional and ultrasonic techniques. The extractability of lac dye from natural origin using power ultrasonic was also evaluated in comparison with conventional heating. The results of dye extraction indicate that power ultrasonic is rather effective than conventional heating at low temperature and short time. Color strength values obtained were found to be higher with ultrasonic than with conventional heating. The results of fastness properties of the dyed fabrics were fair to good [17].

Vankar and Shanker (2008) have extracted coloring pigment from Hollyhock (Alcea rosea) flower and used for dyeing wool yarn, silk and cotton fabrics. It is observed that the dyeing 
with hollyhock gives fair to good fastness properties in sonicator in 1 hour and shows good dye uptake as compared with conventional dyeing [24].

Battu et al. (2010) observed that in wool dyeing at $85^{\circ} \mathrm{C}$ with acid dyes, ultrasound caused an improvement of the dye uptake as much as $25 \%$, or dyeing time would be nearly $20 \%$ shorter than conventional dyeing [25].

Yukseloğlu and Bolat (2010) stated that the wool fabrics have presented similar color yield $(\mathrm{K} / \mathrm{S})$ and acceptable color differences $(\Delta \mathrm{E})$ with the use of ultrasonic energy. Ultrasonic energy was found to be advantageous to be used for wool dyeing at lower temperatures (such as $80^{\circ} \mathrm{C}$ and $90^{\circ} \mathrm{C}$ ) and lower dyeing times (i.e. $80 \mathrm{~min}$. or $90 \mathrm{~min}$.) as an alternative process for conventional dyeing $\left(100^{\circ} \mathrm{C}\right.$ and $\left.144 \mathrm{~min}\right)$ [26].

McNeil and McCall (2011) investigated the effects of ultrasound at $35-39 \mathrm{kHz}$ on several wool dyeing and finishing processes. Ultrasound pre-treatment increased the effectiveness of subsequent oxidative-reductive bleaching, but had no effect on the uptake of acid leveling and acid milling dyes. The pre-treatment retarded the uptake of reactive dye, possibly by increasing the crystallinity of the fiber or removing surface bound lipids. Ultrasound did not improve dyeing under conditions that are currently used in industry, but did show potential to reduce the chemical and energy requirements of dyeing wool with reactive and acid milling dyes, but not acid leveling dyes [27].

Atav and Yurdakul (2011) investigated the effect of ultrasound usage on the color yield in dyeing of mohair fibers. They found that dyeing in the presence of ultrasound energy increases the dye-uptake of mohair fibers and hence higher color yield values are obtained. The difference between the samples dyed in the presence and absence of ultrasound, was greater for darker shades and for dyeing carried out in acidic medium ( $\mathrm{pH} 5$ ), and also for shorter dyeing periods. Furthermore there is no important difference between washing fastness and alkali solubility values of fibers dyed in the presence and absence of ultrasound [28].

Ferrero and Periolatto (2012) studied the possibility of reducing the temperature of conventional wool dyeing with an acid leveling dye using ultrasound in order to reach dye uptake values comparable to those obtained with the standard procedure at $98^{\circ} \mathrm{C}$. Dyeings of wool fabrics were carried out in the temperature range between $60^{\circ} \mathrm{C}$ and $80^{\circ} \mathrm{C}$ using either mechanical or ultrasound agitation of the bath and coupling the two methods to compare the results. For each dyeing, the dye uptake curves of the dye bath were determined and the better results of dyeing kinetics were obtained with ultrasound coupled with mechanical stirring. Finally, fastness tests to rubbing and domestic laundering yielded good values for samples dyed in ultrasound assisted process even at the lower temperature [22].

\section{Ultraviolet technology}

Light is electromagnetic radiation or radiant energy traveling in the form of waves [29]. The electromagnetic spectrum is the range of all possible frequencies of electromagnetic radia- 
tion. The "electromagnetic spectrum" of an object is the characteristic distribution of electromagnetic radiation emitted or absorbed by that particular object. The electromagnetic spectrum extends from low frequencies used for modern radio communication to gamma radiation at the short-wavelength (high-frequency) end, thereby covering wavelengths from thousands of kilometers down to a fraction of the size of an atom [30]. UV energy is found in the electromagnetic spectrum between visible light and x-rays [29].

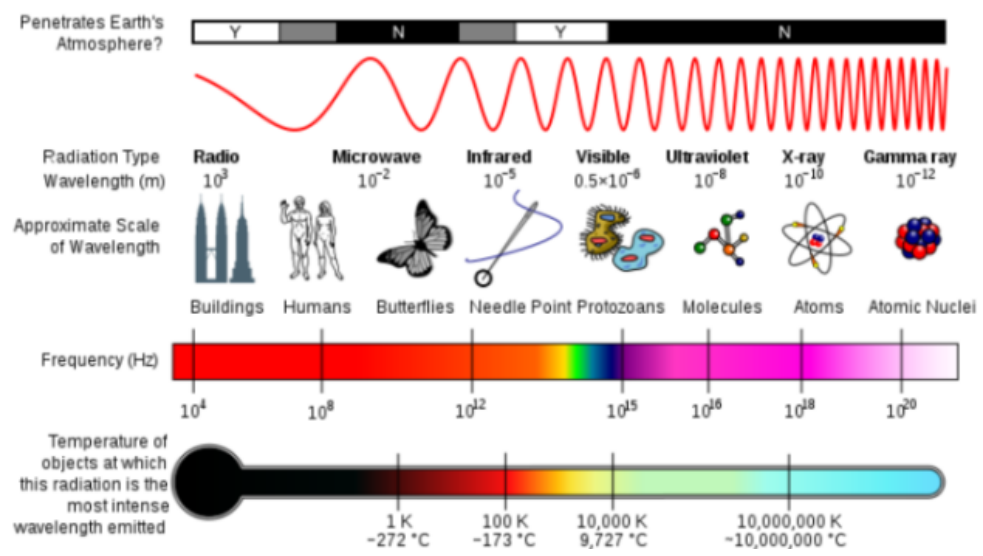

Figure 3. A diagram of the electromagnetic spectrum [30]

Ultraviolet or UV radiation is part of the electromagnetic (light) spectrum that reaches the earth from the sun. It has wavelengths shorter than visible light, making it invisible to the naked eye [31]. Ultraviolet radiation constitutes to $5 \%$ of the total incident sunlight on earth surface (visible light $50 \%$ and IR radiation $45 \%$ ). Even though, its proportion is quite less, it has the highest quantum energy compared to other radiations [32]. Scientists classify UV radiation into three types or bands: UVA, UVB, and UVC (Fig. 4). The ozone layer absorbs some, but not all, of these types of UV radiation [33].

- UVA: Long-wavelength UVA covers the range 315-400 nm. Not significantly filtered by the atmosphere. Approximately $90 \%$ of UV radiation reaching the Earth's surface. UVA is again divided into UVA-I (340 nm - $400 \mathrm{~nm})$ and UVA-II (315 nm - $340 \mathrm{~nm})$ [34].

- UVB: Medium-wavelength UVB covers the range $280-315 \mathrm{~nm}$. Approximately $10 \%$ of UV radiation reaching the Earth's surface [34].

- UVC: Short-wavelength UVC covers the range 100-280 nm [34]. They are the most dangerous among all the rays. However, these rays do not reach the earth's surface as they are completely absorbed by the ozone layer [31].

The deleterious effects of solar irradiation are perceived as changes in texture and color, dryness, etc., and can be evaluated in terms of reduced elasticity, increased porosity or swelling properties, altered 
Visible

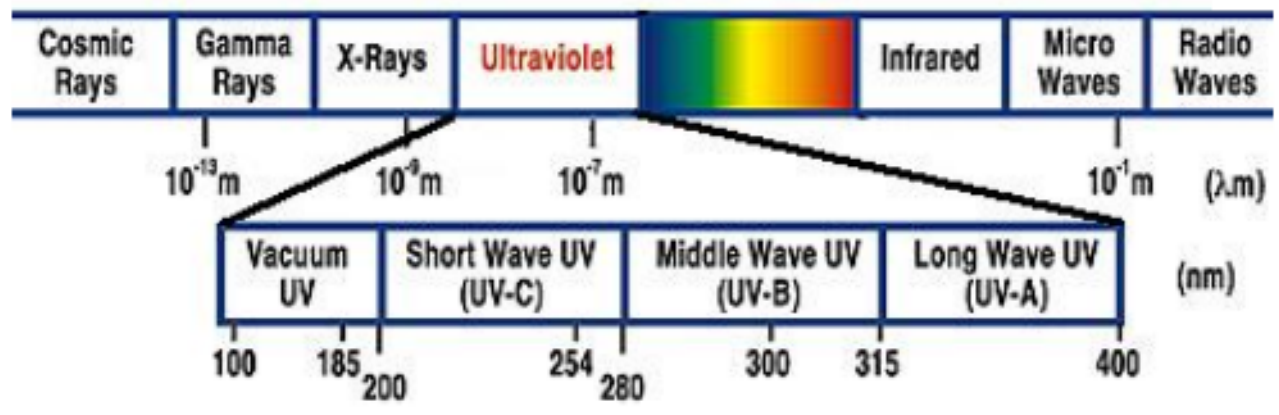

Figure 4. Classification of ultraviolet radiation [35]

dye sorption characteristics, and photofading of natural or artificial hair color [36]. The chemical changes caused by short-term UV irradiation of wool are confined to fibers at the fabric surface and UV is unable to penetrate beyond the surface to weaken the bulk fibers responsible for the mechanical strength. This has enabled the potential application of UV technology as a surface-specific treatment in several areas of wool processing [37]. For wool the UV-absorbing species are aromatic amino acid and cystine residues in the protein structure which absorb strongly below $350 \mathrm{~nm}$. UVC radiation $(200-280 \mathrm{~nm})$ is the most effective range for modifying wool fiber surfaces [38].

The most commercially used process for antifelting and antipilling of wool is based on chlorination. However, recent concern over the release into the environment of adsorbable organohalogens (AOX) in process effluents has prompted the development of alternative, AOX-free processes. Different types of radiation techniques, such as ultraviolet radiation, are utilized as alternatives to chlorination in wool processing [39]. UV treatment can add value in coloration (dyeing and printing), since it is predominantly surface fibers in a fabric that absorb, reflect and scatter light. Photomodification of the surface fibers can allow:

- more dye to become fixed, producing deeper shades

- more rapid fixation of dyes dye fixation under less severe conditions (e.g. lower temperature) [38]

Modification of the dye uptake by exposure of wool fabric to UV radiation before dyeing has been known since the early 1960s. For most dye classes, UV-irradiated fabric takes up significantly more dye than untreated and when fabrics are irradiated through stencils, intricate tone-ontone effects can be produced [37]. Some literature related to the use of ultraviolet technology in dyeing of proteinous fibers is summarized below.

Millington (1998) stated that UV irradiation of wool can significantly increase dyeing color yields. The use of 1:1 metal-complex dyes was found to be particularly effective, and a 3\% o.w.f. dyeing on UV-treated fabric could produce a better depth of shade than a $5 \%$ dyeing on untreated fabric [40]. 
Millington (1998) found that UV radiation of wool fabric exhibits some physical and chemical changes on its surface. This interaction not only modifies the fabric of wool but also improve the shades particularly grey and black. It also helps in even dyeing, deeper shades, chlorine free printing and improve the photo bleaching of wool [41].

Xin et.al (2002) exposed wool samples to UV radiation for $60 \mathrm{~min}$. and investigated the surface modification of the wool fiber by X-ray photoelectron spectroscopy. The chemical change caused by the UV treatment was identified as surface oxidation of cystine (disulphide bonds) and thereby induced changes in the dyeing properties of the wool. The dyeability of UV-treated and untreated wool samples was determined at temperatures of 45, 50, 55 and $60^{\circ} \mathrm{C}$ using C.I. Acid Blue 7. The UV-treated wool samples showed greater levels of dye uptake compared with those of the untreated samples. The adsorption behavior and diffusion coefficients were also studied. The dyeing properties of wool were enhanced by UV radiation due to the increased diffusion coefficient of the dyes in the treated wool fibers [42].

\section{Ozone technology}

Ozone is a natural occurring gas that can be both beneficial and detrimental to organisms on Earth. It is important that sufficient amount of this pale blue gas is present in the stratosphere, where $\mathrm{O}_{3}$ molecules would shield most of the UV radiation from reaching Earth [43]. Although ozone is a blue colored gas at normal temperatures and pressures; because of its low concentrations in its applications the observation of this blue color of ozone is impossible [44]. Ozone gas has a pungent odor readily detectable at concentrations as low as 0.02 to 0.05 ppm (by volume), which is below concentrations of health concern [45].

Ozone was first generated and characterized by a German scientist named Schonbein in 1840 [46]. Ozone is a nonlinear triatomic molecule possessing two interoxygen bonds of equal length (1.278 A) and an average bond angle of $116^{\circ} 49^{\prime}$ [47].
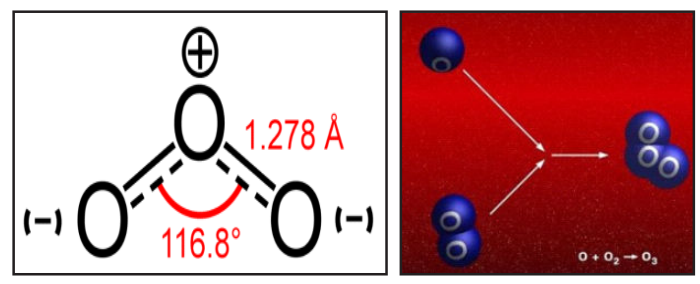

Figure 5. Ozone molecule [48, 49]

Ozone is formed naturally in the atmosphere by photochemical reaction with solar UV radiation and by lightening. It can also be generated artificially. Three most common ways of generating ozone artificially are: 
- Corona discharge: In this method, ozone is generated when free, energetic electrons in the corona dissociate oxygen molecules in oxygen-containing feed gas that passes through the discharge gap of the ozone generator.

- UV light: Ozone can also be generated by UV light. The high energy UV light ruptures the oxygen molecules into oxygen atoms, and the subsequent combination of an oxygen atom with an oxygen molecule produces ozone $\left(\mathrm{O}_{3}\right)$.

- Electrolysis: A third method for generating ozone is electrolysis, which uses an electrolytic cell. Specifically, electrolysis involves converting oxygen in the water to ozone by passing the water through positively and negatively charged surfaces [46].

Ozone is a very powerful oxidizing agent, which is able to participate in a great number of reactions with organic and inorganic compounds. Among the most common oxidizing agents, it is only surpassed in oxidant power by fluorine and hydroxyl radicals (see Table 1) [50]. Ozone has strong tendency to react with almost any organic substance as well as with water. The reaction proceeds via several intermediates such as peroxides, epoxides and perhydroxyl and hydroxyl radicals [51].

\begin{tabular}{cccc}
\hline Oxidation species & Oxidation power (V) & Oxidation species & Oxidation power (V) \\
\hline Fluorine & 3.03 & Chlorine dioxide & 1.50 \\
\hline Hydroxyl radical & 2.80 & Hypochlorous acid & 1.49 \\
\hline Atomic oxygen & 2.42 & Hypoiodous acid & 1.45 \\
\hline Ozone & 2.07 & Chlorine & 1.36 \\
\hline Hydrogen peroxide & 1.77 & Bromide & 0.54 \\
\hline Permanganate & 1.67 & lodine & \\
\hline Hypobromous acid & 1.59 & & 1.09 \\
\hline
\end{tabular}

Table 1. Oxidation power of selected oxidizing species [50]

In an ozonation process two possible pathways have to be considered [50]: direct oxidation with ozone molecules or the generation of free-radical intermediates, such as the $\mathrm{OH}$ radical, which is a powerful, effective, and non-selective oxidizing agent [52].

$$
\begin{gathered}
\mathrm{O}_{3}+\mathrm{H}_{2} \mathrm{O} \rightarrow 2 \mathrm{HO}_{2} \\
\mathrm{O}_{3}+\mathrm{HO}_{2} \bullet \rightarrow \mathrm{HO} \bullet+2 \mathrm{O}_{2}
\end{gathered}
$$

Molecular ozone can directly react with dissolved pollutants by electrophilic attack of the major electronic density positions of the molecule. This mechanism will take place with pollutants such as phenols, phenolates or tiocompounds. The radical mechanism predominates 
in less reactive molecules, such as aliphatic hydrocarbons, carboxylic acids, benzenes or chlorobenzenes [50].

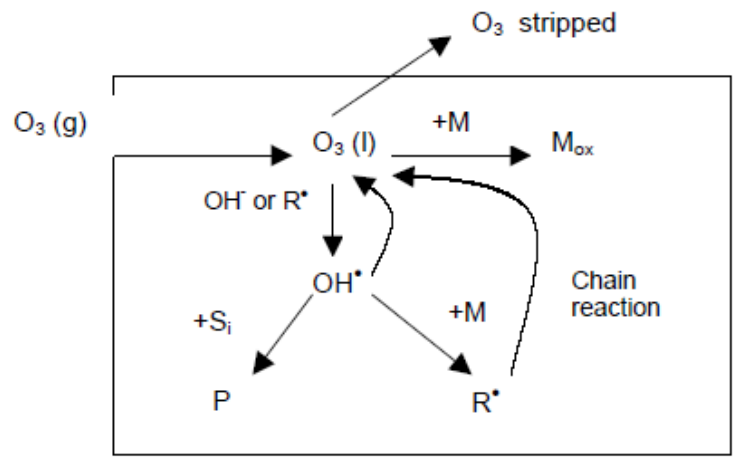

Direct-reaction

$\mathrm{R}=$ free radicals, which catalyze the ozone decomposition

$\mathrm{M}=$ solute

$\mathrm{S}_{\mathrm{i}}=$ free radical scavenger

$\mathrm{M}_{\mathrm{ox}}=$ oxidized solute

$\mathrm{P}=$ products, which do not catalyze the ozone decomposition

Radical-type reaction

Figure 6. Scheme of reactions of ozone added to an aqueous solution [50]

The chlorine/ Hercosett process, the most widely used treatment for the wool dyeing process, causes dangerous ecological problems due to the contamination of waste water with absorbable organic halides (AOX). Because of legal restrictions and national and international awareness of ecology and pollution control, an AOX-free pretreatment is required to offer environmental advantages [53]. Alternative surface modifications for improving wool dyeability are therefore being explored. One of them is ozonation process [54]. Ozone treatments of proteinous fibers such as wool, mohair, angora and silk have been investigated by many authors. When literature is examined, it can be well understood that, increase in dyeability of protenious fibers caused by ozonation process depends on the following parameters;

- $\mathrm{pH}$ : Typically, at $\mathrm{pH}<4$ direct ozonation dominates and above $\mathrm{pH}>9$ the indirect pathway dominates. In the range of $\mathrm{pH} 4-9$, both of them are important. The $\mathrm{pH}$ influences the generation of hydroxyl radicals [55].

$$
\begin{gathered}
\mathrm{O}_{3}+\mathrm{OH}^{-} \rightarrow \mathrm{O}_{3}^{-} \bullet+\mathrm{OH} \bullet \\
\mathrm{O}_{3}^{-} \bullet \rightarrow \mathrm{O}^{-} \bullet+\mathrm{O}_{2} \\
\mathrm{O}^{-} \bullet+\mathrm{H}^{+} \rightarrow \mathrm{OH} \bullet
\end{gathered}
$$

Generally at neutral medium reaction rate of ozone gas is slow due to its low solubility. While molecular ozone reacts at low $\mathrm{pH}$ values, at high $\mathrm{pH}$ values radicals react. Since the oxidation potential of hydroxyl radicals exceeds that of ozone molecules, oxidation is faster in indirect reactions. Additionally $\mathrm{HO} \bullet$ is not the only radical that is formed. Even though 
the $\mathrm{HO} \bullet$ radical is the most powerful radical with a $2.8 \mathrm{~V}$ oxidation potential, $\mathrm{HO}_{2} \bullet, \mathrm{HO}_{3} \bullet$ and $\mathrm{HO}_{4} \bullet$ radicals are also formed as shown in Eq. 6-11 [56].

$$
\begin{gathered}
\mathrm{O}_{3}+\mathrm{OH}^{-} \rightarrow \mathrm{HO}_{2} \bullet+\mathrm{O}_{2}^{-} \\
\mathrm{HO}_{2} \bullet \leftrightarrow \mathrm{O}^{-} \bullet+\mathrm{H}^{+} \\
\mathrm{O}_{3}+\mathrm{O}_{2} \cdot \bullet \rightarrow \mathrm{O}_{3}^{-}+\mathrm{O}_{2} \\
\mathrm{O}_{3}^{-}+\mathrm{H}^{+} \rightarrow \mathrm{HO}_{3} \\
\mathrm{HO}_{3} \bullet \rightarrow \mathrm{HO}^{-}+\mathrm{O}_{2} \\
\mathrm{HO} \bullet+\mathrm{O}_{3} \rightarrow \mathrm{HO}_{4}
\end{gathered}
$$

At $\mathrm{pH}<9$, the highly selective ozone molecules react rapidly at sites of high electron density (such as aliphatic and aromatic double bonds) and slowly at less reactive sites (such as C-H bonds of saturated hydrocarbons). The presence of the $\bullet \mathrm{OH}$ radicals above $\mathrm{pH} 9$ have less selectivity and high oxidation potential $(2.8 \mathrm{~V})$ [51]. Ozonation efficiency decreases in the basic $\mathrm{pH}$ values when compared to acidic and neutral $\mathrm{pH}$. Because in a basic solution, more hydroxide ions are present and these hydroxide ions act as an initiator for the decay of ozone [57]. Moreover, it is reported that the dissolved ozone concentration in water decreases from $4.3 \times 10^{-4} \mathrm{~mol} / \mathrm{L}$ at $\mathrm{pH} 4$ to $1.5 \times 10^{-4} \mathrm{~mol} / \mathrm{L}$ at $\mathrm{pH} 10$ [58].

- Temperature: As temperature increases, ozone becomes less soluble (see Table 2) [45]; however, it can not be said that ozonation efficiency reduces with the decrease in the solubility of ozone, because temperature rise also increases the reaction rate [56].

\begin{tabular}{cc}
\hline Temperature $\left({ }^{\circ} \mathbf{C}\right)$ & Solubility $\left(\mathbf{k g} \cdot \mathbf{m}^{-3}\right)$ \\
\hline 0 & 1,09 \\
\hline 10 & 0,78 \\
\hline 20 & 0,57 \\
\hline 30 & 0,40 \\
\hline 40 & 0,27 \\
\hline 50 & 0,19 \\
\hline 60 & 0,14 \\
\hline
\end{tabular}

Table 2. Water solubility of ozone [59] 
- Ozone dose: Because oxidation reactions are caused by molecular ozone or radical species formed by the reactions of ozone, with the increase in ozone dose ozonation efficiency increases [56]

- Water content of the fiber: In literature it was stated that the rate of oxidation is accelerated by the hydration of hydrophilic groups in the fiber and above a critical level of moisture content (at which fiber is completely hydrated) it is retarded by the water which enters the intermicellar and interfibrillar space. In many previous studies, the importance of water during ozonation process was reported [51, 57, 58]. Prabaharan and Rao have suggested a model in order to explain this phenomenon. According to this model it can be said that for ozonation to take place, water should be present inside of the fiber. However the quantity of water present has a definite effect on the rate of reaction [51].

Fig. 7 gives the schematic representation of ozone path from gas phase to reaction site in the fiber. When sufficient water is not present, $d_{1}$ and $d_{2}$ are absent and hence $O$ is transported by convection across the distances $d_{1}$ and $d_{2}$ and then by diffusion across $d_{3}$ and $d_{4}$. Since sufficient water is not supplied, entire hydrophilic group in the fiber is not hydrated and hence the extent of attack at $R$ is low. When sufficient water is supplied, $d_{1}$ is absent and $d_{2}$ is either fully or partially absent depending on the quantity of water available and hence $\mathrm{O}$ is transported by convection across $d_{1}$ and convection or diffusion across $d_{2}$ followed by diffusion across $d_{3}$ and $d_{4}$. Since sufficient water is supplied, entire hydrophilic group in the fiber is hydrated and hence the extent of attack at $\mathrm{R}$ is maximum. When excess water is present, $d_{1}$ and $d_{2}$ are present and hence $O$ is transported by diffusion across $d_{1}, d_{2}, d_{3}$, and $d_{4}$. Since excess water is present at $d_{1}$ and $d_{2}$, dilution of ozone takes place and hence ozone attack at $\mathrm{R}$ is lower in spite of complete hydration at $\mathrm{d}_{3}$ [58].

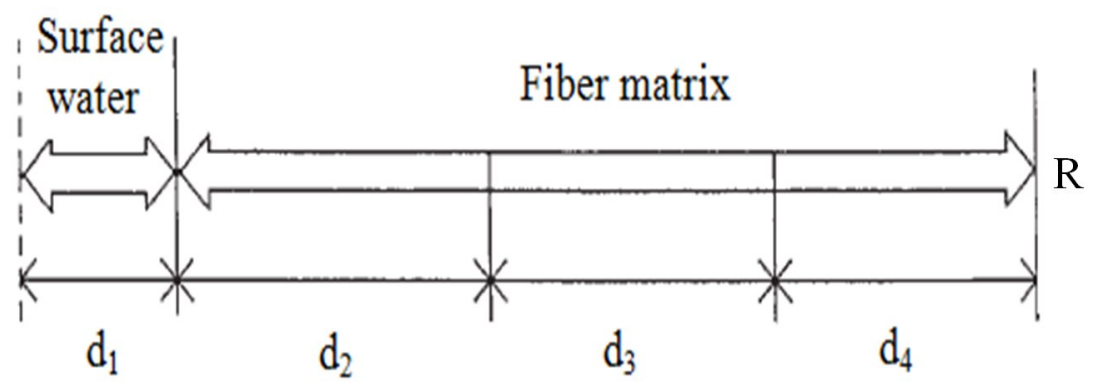

Figure 7. Schematic representation of ozone path from gas phase to reaction site [58]; ( $d_{1}$ : the distance occupied by surface water, $d_{2}$ : the distance occupied by mobile water phase, $d_{3}$ : immobile water phase, $d_{4}$ : the distance between the immobile water phase and R)

Some literature related to the effect of ozonation on dyeing properties of various proteinous fibers is summarized below.

Micheal and El-Zaher (2003) has evaluated the effect of ultraviolet/ozone treatments for different times on the characteristics of wool fabrics with respect to wettability, permeability, yel- 
lowness index, and weight loss. The beneficial effects of this treatment on dyeability, color parameters, light fastness characteristics, and the change in color difference after exposure of the treated dyed samples to artificial daylight for about 150 hours were investigated. The results indicated that the improvement in wetting processes may have been due to surface modifications; this meant that an increase in the amorphousity of the treated samples, the oxidation of the cystine linkage on the surface of the fabrics, and the formation of free-radical species encouraged dye uptake [60].

Sargunamani and Selvakumar (2007) investigated the effects of process parameters (pick-up value, $\mathrm{pH}$ and time) in the ozone treatment of raw and degummed tassar silk fabrics on their properties such as yellowness index, breaking strength, breaking elongation, weight, amino group content. Decrease in yellowness index, breaking strength, breaking elongation, and weight as well an increase in amino group content was observed [58].

Perincek et.al (2008) investigated a novel bleaching technique for Angora rabbit fiber. For this purpose, a detailed investigation on the role of the fiber moisture, $\mathrm{pH}$, and treatment time during ozonation was carried out. Also, the effect of ozonation on the dyeing properties of Angora rabbit fibers was researched. Consequently, it was found that ozonation improved the degree of whiteness and dyeability of Angora rabbit fiber [57].

Atav and Yurdakul (2010) investigated the use of ozonation to achieve dyeability of the angora fibers at lower temperatures without causing any decrease in dye uptake by modifying the fiber surfaces. The study was carried out with known concentration of ozone, involving process parameters such as wet pick-up (WP), $\mathrm{pH}$, and treatment time. The effect of fiber ozonation was assessed in terms of color, and test samples were also evaluated using scanning electron microscopy (SEM). The optimum conditions of ozonation process were determined as WP 60\%, pH 7 and $40 \mathrm{~min}$. According to the experimental results it can be concluded that, ozonated angora fibers can be dyed at $90^{\circ} \mathrm{C}$ with acid and reactive dye classes without causing any decrease in color yield [61]. In an other study on ozonation process carried out by Atav and Yurdakul (2011) the optimum conditions for mohair fiber were determined as WP 60\%, pH 7 and $30 \mathrm{~min}$. Dyeing kinetics also studied and it was demonstrated that the rate constant and the standard affinity of ozonated sample increased [54].

\section{Plasma technology}

Faraday proposed to classify the matter in four states: solid, liquid, gas and radiant. Researches on the last form of matter started with the studies of Heinrich Geissler (1814-1879): the new discovered phenomena, different from anything previously observed, persuaded the scientists that they were facing with matter in a different state. Crookes took again the term "radiant matter" coined by Faraday to connect the radiant matter with residual molecules of gas in a low-pressure tube. Sufficient additional energy, supplied to gases by an electric field, creates plasma [62]. The plasma is referred to as the fourth state of matter (in addition to solid, liquid, gaseous) [63]. 


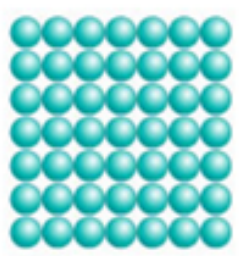

Solid

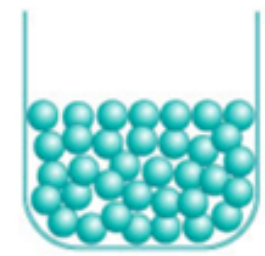

Liquid

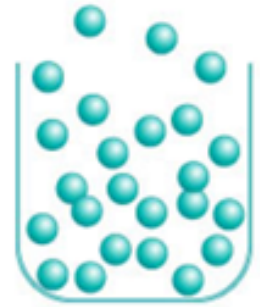

Gas

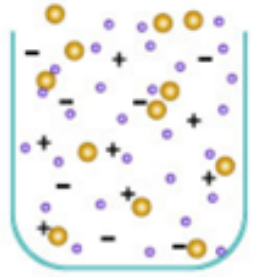

Plasma

Figure 8. States of matter [64]

The plasma is an ionized gas with equal density of positive and negative charges which exist over an extremely wide range of temperature and pressure [65]. As shown in Fig. 9, the plasma atmosphere consists of free electrons, radicals, ions, UV-radiation and a lot of different excited particles in dependence of the used gas [66].

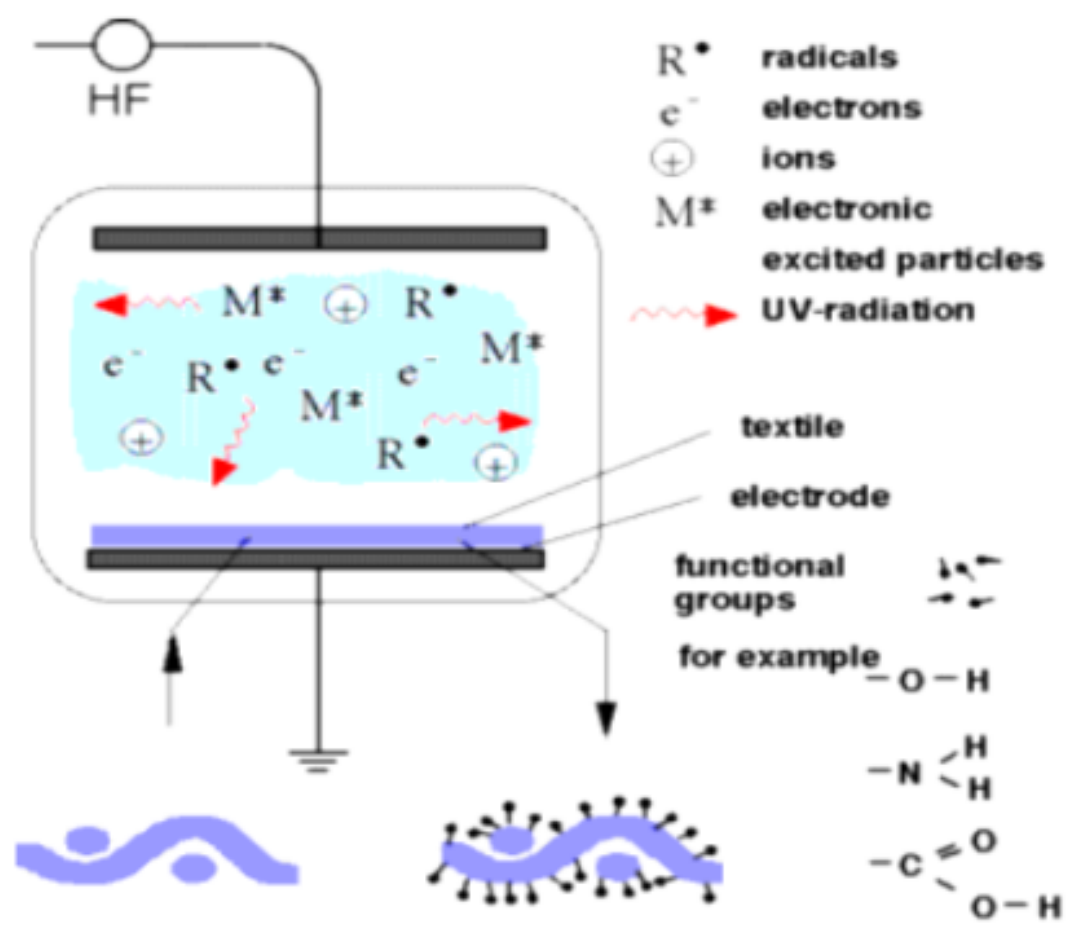

Figure 9. The principle of the plasma treatment [66] 
There are different methodologies to induce the ionization of plasma gas for textile treatment [65]:

- Glow Discharge: It is the oldest type of plasma; it is produced at reduced pressure and assures the highest possible uniformity and flexibility of any plasma treatment [67]. The methodology applies direct electric current, low frequency over a pair of electrodes [65]. Alternatively, a vacuum glow discharge can be made by using microwave $(\mathrm{GHz})$ power supply [68].

- Corona Discharge: It is formed at atmospheric pressure by applying a low frequency or pulsed high voltage over an electrode pair [65]. Typically, both electrodes have a large difference in size. The corona consists of a series of small lightning-type discharges. High local energy levels and problems related to the homogeneity of the classical corona treatment of textiles make it problematic in many cases [68].

- Dielectric-Barrier Discharge: DBD is produced by applying a pulsed voltage over an electrode pair of which at least one is covered by a dielectric material [65]. Although lightning-type discharges are created, a major advantage over corona discharges is the improved textile treatment uniformity [68].

Practically, one generates the plasma by applying an electrical field over two electrodes with a gas in between. This can be carried out at atmospheric pressure or in a closed vessel under reduced pressure. In both cases, the properties of the plasma will be determined by the gasses used to generate the plasma, as well as by the applied electrical power and the electrodes (material, geometry, size, etc.). The pressure of the gas will have a large influence on the plasma properties but also on the type of equipment needed to generate the plasma [69].

The plasmas can be classified as being of the low pressure and atmospheric type. Both plasmas can be used for the surface cleaning, surface activation, surface etching, cross linking, chain scission, oxidation, grafting, and depositing of materials, and generally similar effects are obtained; however, atmospheric plasma has many advantages when compared with vacuum plasma [70]. Low pressure plasmas are typically in the pressure range of $0.01 \mathrm{kPa}$. A vacuum chamber and the necessary vacuum pumps are required, which means that the investment cost for such a piece of equipment can be high. These plasmas are characterized by their good uniformity over a large volume. Atmospheric plasmas operate at standard atmospheric pressure $(\sim 100 \mathrm{kPa})$. Open systems using the surrounding air exist. The range of processes is not as wide as for low pressure plasmas. On the other hand, these systems are easily integrated in existing finishing lines, a major advantage from industrial view point. Of course, for an inline process to be feasible, the plasma treatment has to be done at sufficiently high line speeds, which is not evident for textile materials [69].

Due to increasing requirements on the finishing of textile fabrics, increasing use of technical textiles with synthetic fibers, as well as the market and society demand for textiles that have been processed by environmentally sound methods, new innovative production techniques are demanded [66]. Plasma technology is an important alternative to wet treatments, because there is no water usage, treatment is carried out in gas phase, short treatment time is enough, it does not cause industrial waste, and it provides energy saving [71]. In Cold plas- 
ma, that is, low-temperature plasma (LTP) treatment is the most commonly used physical method for a surface specific fiber modification, as it affects the surface both physically and chemically [72]. The advantage of such plasma treatments is that the modification turns out to be restricted in the uppermost layers of the substrate, thus not affecting the overall desirable bulk properties [62].

The plasma gas particles etch on the fabric surface in nano scale so as to modify the functional properties of the fabric. Unlike conventional wet processes, which penetrate deeply into fibers, plasma only reacts with the fabric surface and does not affect the internal structure of the fibers. Plasma technology modifies the chemical structure as well as the topography of the textile material surface. In conclusion, plasma can modify the surface properties of textile materials, deposit chemical materials (plasma polymerization) to add functionality, or remove substances (plasma etching) from the textile materials [65]. Essentially, four main effects can be obtained depending on the treatment conditions;

- The cleaning effect: It means the removal of impurities or substrate material from the exposed surface [73]. It is mostly combined with changes in the wettability and the surface texture. This leads for example to an increase in dye-uptake.

- Increase of microroughness: This affects, for example, an anti-pilling finishing of wool.

- Generation of radicals: Presence of free radicals induces secondary reactions like crosslinking. Furthermore, graft polymerization can be carried out as well as reaction with oxygen to generate hydrophilic surfaces [66].

- Plasma polymerization: In plasma polymerization, a monomer is introduced directly into the plasma and the polymerization occurs in the plasma itself [73]. It enables the deposition of solid polymeric materials with desired properties onto the substrates [66].

When a surface is exposed to plasma a mutual interaction between the gas and the substrate takes place. The surface of the substrate is bombarded with ions, electrons, radicals, neutrals and UV radiation from the plasma while volatile components from the surface contaminate the plasma and become a part of it. Whatever may be the final outcome on the surface, the basic effect that causes modification is based on the radical formation (attachment of functional group and deposition/polymerization) and etching phenomena. Fig. 10 illustrates the mechanism of plasma modification [74].

Low temperature plasma treatment of wool has emerged as one of the environmental friendly surface modification method for wool substrate. The efficiency of the low temperature plasma treatment is governed by several operational parameters like;

- Nature of the gas used

- System pressure

- Discharge power

- Duration of treatment 
Plasma treatment can impart anti-felting effect, degreasing, improved dyestuff absorption and increased wetting properties to wool fibers [68]. These effects of the plasma process are attributed to several changes in the wool surface, such as;

- the formation of new hydrophilic groups (sulphonate and carboxylate),

- partial removal of covalently bonded fatty acids belonging to the outermost surface of the fiber, and

- the etching effect [75].

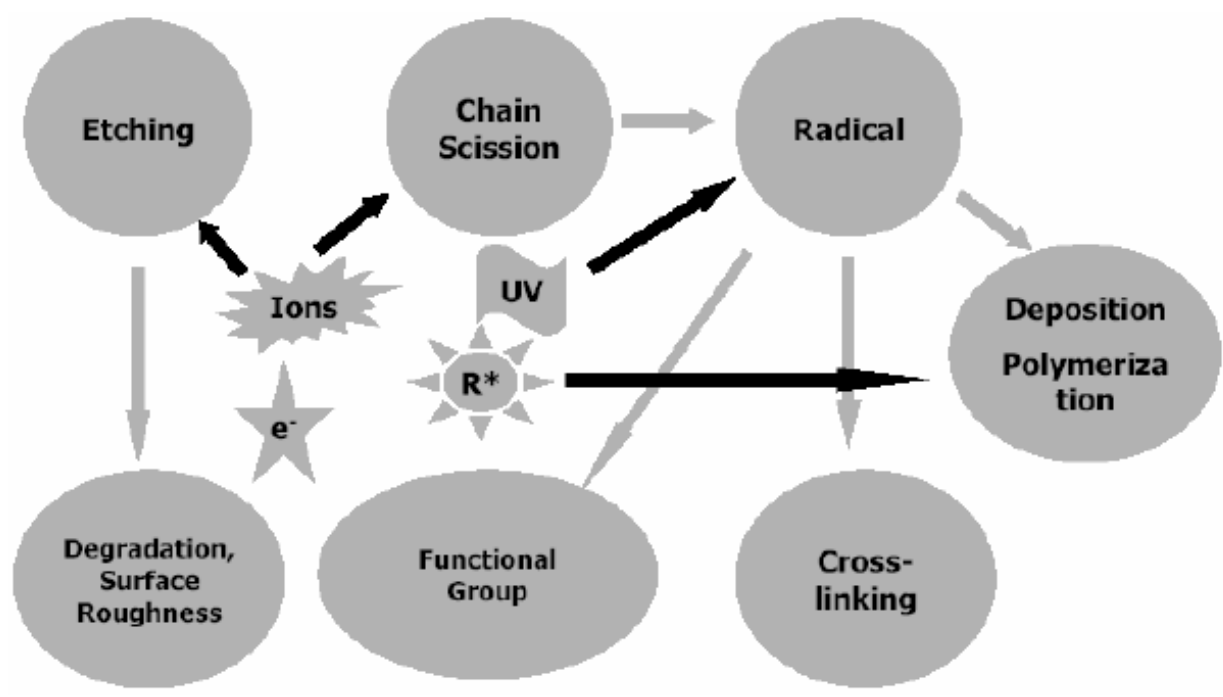

Figure 10. Mechanism of plasma-substrate interaction [74]

Plasma treatments modify the fatty acid monolayer present in the outermost part of the wool fiber, generating new hydrophilic groups as a result of the hydrocarbon chain oxidation and reducing the fatty acid chain length. The oxidation process also promotes the formation of Bunte salt and cysteic acid residues on the polypeptide chain. Particularly when oxidizing gasses are used, plasma induces cystine oxidation in the A-layer of the exocuticle, converting it into cysteic acid and thus reducing the number of crosslinkages in the fiber surface [72]. As the surface is oxidized, the hydrophobic character is changed to become increasingly hydrophilic [76]. The etching of the hydrophobic epicuticle and increase in surface area also contributes towards the improvement in the ability of the fibers to wet more easily [74].

Plasma treatment of wool fibers causes improvement in dyeability of wool fibers due to the changes occurred on fiber surface. For this reason dyeing kinetics, dye uptake and hence 
depth of shade are increased. In literature there are many studies related to the effect of plasma treatment on dyeability of proteinous fibers. Some of them are summarized below.

Wakida et al. (1993) treated the merino wool top with low-temperature plasmas of helium/ argon and acetone/argon under atmospheric pressure for 30 seconds and then dyed with two leveling acid dyes, and two milling acid dyes. Dyeing rate and final dye uptake increased with the atmospheric low-temperature plasma treatments. In particular, helium/ argon plasma was found to be much more effective than acetone/argon plasma at improving dyeing properties [77].

Yoon et al. (1996) treated the wool fabrics with low temperature oxygen plasma and examined their mechanical and dyeing properties. Plasma pretreatment caused an increase in strength. Furthermore, it was observed that when wool was dyed with a leveling acid dye, equilibrium dye uptake did not change, but the dyeing rate increased with a milling acid dye [78].

Jing (1996) investigated the surface modification of silk fabric by plasma graft copolymerization with acrylamide and acrylic acid. The dependence of graft degree was examined on the conditions of plasma grafting. The relationships were discussed between graft degree and factors such as crease recovery, dyeability, colour fastness and mechanical properties. It was shown that the dyeability and color fastness have been improved for samples grafted with acrylic acid [79].

Wakida et al. (1996) treated wool fibers with oxygen low-temperature plasma and then dyed with acid and basic dyes. Despite the increase of electronegativity of the fiber surface caused by the plasma treatment, the rate of dyeing of wool was increased with both dyes [80].

Wakida et al. (1998) treated wool fabrics with oxygen, carbon tetrafluoride, and ammonia low temperature plasmas and then dyed with several natural dyes. The dyeing rate of the plasma-treated wool increased considerably with cochineal, Chinese cork tree, and madder, but not with gromwell. Furthermore, plasma-treated wool fabrics dyed with cochineal and Chinese cork tree have increased brightness compared with untreated wool [81].

Kan et al. (1998) investigated the induced surface properties of wool fabrics created by the sputtering of low-temperature plasma treatment, such as surface luster, wettability, surface electrostatic and dyeability. After the low-temperature plasma treatment, the treated wool fabric specimens exhibited better hydrophilicity and surface electrostatic properties at room temperature, together with improved dyeing rate. The occurrence of some grooves on the fiber specimens was determined by scanning electron microscope and it was stated that these grooves might possibly provide a pathway for a faster dyeing rate [82].

Kan et al. (1998) treated the wool fiber with low-temperature plasma (LTP) using different non-polymerising gases and dyed with chrome dye. The rate of dyeing, the time of half-dyeing $\left(t_{1 / 2}\right)$, the final dye uptake, the chromium exhaustion and the chromium fixation were studied. The results showed that LTP treatments can alter the dyeing properties to various degrees. The nature of the LTP gases plays an important role in affecting the behavior of chrome dyeing [83]. 
Kan et al. (1999), have studied the influence of the nature of gas (oxygen, nitrogen, and a $25 \%$ hydrogen/75\% nitrogen gas mixture) in plasma treatments on the fiber-to-fiber friction, feltability, fabric shrinkage, surface structure, dyeability, alkali solubility, and surface chemical composition properties of wool substrates. After the low temperature plasma (LTP) treatment, those properties of the LTP-treated substrates changed, and the changes depended on the nature of the plasma gas used [84]. Kan et al. (1999), have also searched the surface characteristics of wool fibers treated with LTP with different gases, namely, oxygen, nitrogen and gas mixture (25\% hydrogen / $75 \%$ nitrogen). Investigations showed that chemical composition of wool fiber surface varied differently with the different plasma gas used. The surface chemical composition of the different LTP-treated wool fibers was evaluated with different characterization methods, namely FTIR-ATR, XPS and saturated adsorption value [85].

Iriyama et al. (2002) treated the silk fabrics with $\mathrm{O}_{2}, \mathrm{~N}_{2}$, and $\mathrm{H}_{2}$ plasmas for deep dyeing and good color fastness to rubbing. C.I. Reactive Black 5 was used as a dye, and color was evaluated by total K/S. All plasma-treated silk fabrics showed weight loss, especially by $\mathrm{O}_{2}$ plasma. Total K/S of dyed silk fabrics treated at $60 \mathrm{~Pa}$ of all plasmas was improved greatly. Total $\mathrm{K} / \mathrm{S}$ increased with increasing plasma treatment time, weight loss of the fabrics in the treatment, and dye concentration in dyeing. They gained greater total K/S even dyed in $6 \%$ of dye concentration compared with untreated one dyed in $10 \%$. Color fastness to wet rubbing of silk fabrics was not improved by plasma treatment. However, most of them were still within the level for commercial use [86].

Sun and Stylios (2004), have investigated the effects of LTP on pre-treatment and dyeing processes of cotton and wool. The contact angles, wicking properties, scourability, and dyeability of fabrics were affected by low-temperature plasma treatments. After treatment, the dye uptake rate of plasma treated wool has been shown to increase. It has been shown that $\mathrm{O}_{2}$ plasma treatment increases the wetability of wool fabric and also the disulphide linkages in the exocuticle oxidize to form sulphonate groups which also enhances the wetability [87].

Binias et al. (2004) have investigated the effect of low temperature plasma on some properties (surface characteristic, water absorption capacity, capillarity, dyeability) of wool fibers. Selected properties of wool textiles were changed by the influence of low-temperature plasma on the fiber's surface layers, acting only on a very small thickness. The level of changes was limited by parameters of the low-temperature plasma. Lowering of the dyeing temperature was achieved [88].

Jocic et al. (2005), have investigated the influence of low-temperature plasma and biopolymer chitosan treatments on wool dyeability. Wool knitted fabrics were treated and characterized by whiteness and shrink-resistance measurements. Surface modification was assessed by contact-angle measurements of human hair fibers. It was stated that after plasma treatment the whiteness degree and hydrophility of fibers increased and fiber dyeability was improved [71].

Sun and Stylios (2005), have determined the mechanical and surface properties and handle of wool and cotton fabrics treated with LTP. This investigation showed that the mechanical 
properties of wool changed remarkably after oxygen plasma treatment. There were no significantly observed differences between plasma treated and un-treated fabrics after scouring and dyeing [89].

Masukuni and Norihiro (2006), studied the dyeing properties of Argon (Ar)-plasma treated wool using the six classes of dyestuffs, i.e., acid, acid metal complex, acid mordant, reactive, basic and disperse dyes. Ar-plasma treatment greatly improved the color yield and levelness, together with the decrease of tippy dyeing. A condition in the plasma treatment enhanced not only the color yield but also the anti-felting performance. The relationship between the improvement of dyeing properties by the plasma treatment and the chemical structure of the dyes was also examined. In the case of the acid dyes, the effect of plasma treatment on color yield was more significant for the milling type dyes with large molecular weight than the leveling type dye with low molecular weight. Furthermore, the hot water and rubbing fastness were improved by Ar-plasma treatment [90].

Kan and Yuen (2006) treated the wool fibers with oxygen plasma and then dyed these fibers with acid, chrome and reactive dye. For acid dyeing, the dyeing rate of the LTP-treated wool fiber was greatly increased, but the final dye uptake equilibrium did not show any significant change. For the chrome dyeing, the dyeing rate of the LTP-treated wool fiber was also increased, but the final dye uptake equilibrium was only increased to a small extent. For the reactive dyeing, the dyeing rate of the LTP-treated wool fiber was greatly increased, and the final dye uptake equilibrium was also increased significantly [91].

El-Zawahry et al. (2007) investigated the impact of plasma-treatment parameters on the surface morphology, physical-chemical, and dyeing properties of wool using anionic dyes. The LTP-treatment resulted in a dramatic improvement in fabric hydrophilicity and wettability, the removal of fiber surface material, and creation of new active sites along with improved initial dyeing rate. The nature of the plasma gas governed the final uptake percentage of the used acid dyes according to the following descending order: nitrogen plasma > nitrogen/ oxygen (50/50) plasma $>$ oxygen plasma $>$ argon plasma $\geq$ control. Prolonging the exposure time up to 20 minutes resulted in a gradual improvement in the extent of uptake [92].

Demir et al. (2008), were treated the knitted wool fabrics with atmospheric argon plasma, enzyme (protease), chitosan and a combination of these processes. The treated fabrics were evaluated in terms of their dyeability, color fastness and shrinkage properties, as well as bursting strength. The surface morphology was characterized by SEM images. In order to show the changes in wool surface after plasma treatment, XPS analysis was done. According to the experimental results it was stated that atmospheric plasma has an etching effect and increases the functionality of a wool surface [93].

Chvalinova and Wiener (2008) investigated the effects of atmospheric pressure plasma treatment on dyeability of wool fabric. Untreated and plasma treated wool materials were dyed with acid dye in weak acid solution ( $\mathrm{pH}$ 6). Experiments showed invasion of surface layer of cuticle by plasma and it was observed that the plasma treated wool fabric for 100 seconds, absorbed double more dye than untreated wool fabric [94]. 
Naebe et al. (2010) treated the wool fabric with atmospheric-pressure plasma with helium gas for 30 seconds. X-ray photoelectron spectroscopy and time-of-flight secondary ion mass spectrometry confirmed removal of the covalently-bound fatty acid layer (F-layer) from the surface of the wool fibers, resulting in exposure of the underlying, hydrophilic protein material. Dye uptake experiments were carried out at $50^{\circ} \mathrm{C}$ to evaluate the effects of plasma on the rate of dye uptake by the fiber surface, as well as give an indication of the adsorption characteristics in the early stages of a typical dyeing cycle. The dyes used were typical, sulfonated wool dyes with a range of hydrophobic characteristics, as determined by their partitioning behavior between water and n-butanol. No significant effects of plasma on the rate of dye adsorption were observed with relatively hydrophobic dyes. In contrast, the relatively hydrophilic dyes were adsorbed more rapidly (and uniformly) by the plasma-treated fabric [95].

Demir (2010) treated the mohair fibers by air and argon plasma for modifying their some properties such as hydrophilicity, grease content, fiber to fiber friction, shrinkage, dyeing, and color fastness. The results showed that the atmospheric plasma has an etching effect and increases the functionality of a fiber surface. The hydrophilicity, dyeability, fiber friction coefficient, and shrinkage properties of mohair fibers were improved by atmospheric plasma treatment [96].

Atav and Yurdakul (2011) investigated the use of plasma treatment for the modification of fiber surfaces to achieve dyeing of mohair fibers at lower temperatures without decreasing dye uptake. The study was carried out by using different gases under various powers and times. The effect was assessed in terms of color. Test samples were also evaluated using scanning electron microscopy (SEM). The optimum conditions of plasma treatment for improving mohair fiber dyeability, is treatments carried out by using Ar gas at $140 \mathrm{~W}$ for $60^{\prime \prime}$. According to the experimental results it can be concluded that plasma treated mohair fibers can be dyed at lower temperatures $\left(90^{\circ} \mathrm{C}\right)$ shorter times $(1 \mathrm{~h}$ instead of $1.5 \mathrm{~h})$ with reactive dyes without decreasing color yield. Dyeing kinetics was also searched in the study and it was demonstrated that the rate constant and the standard affinity of plasma treated sample was increased [97].

\section{Gamma irradiation technology}

Gamma radiation, also known as gamma rays or hyphenated as gamma-rays and denoted as $\gamma$, is electromagnetic radiation of high frequency and therefore energy. Gamma rays typically have frequencies above 10 exahertz (or $>10^{19} \mathrm{~Hz}$ ), and therefore have energies above $100 \mathrm{keV}$ and wavelengths less than 10 picometers (less than the diameter of an atom) [98]. Gamma rays are identical in nature to other electromagnetic radiations such as light or microwaves but are of much higher energy. Examples of gamma emitters are cobalt-60, zinc-65, cesium-137, and radium-226. Like all forms of electromagnetic radiation, gamma rays have no mass or charge and interact less intensively with matter than ionizing particles [99]. 


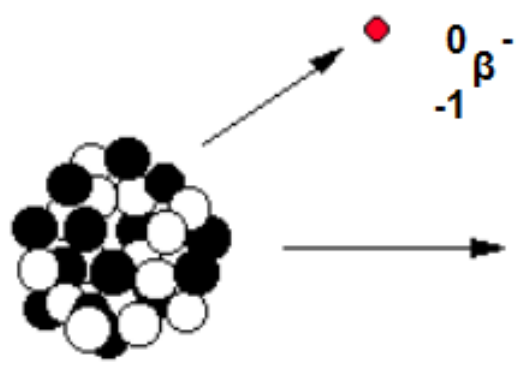

Co-60

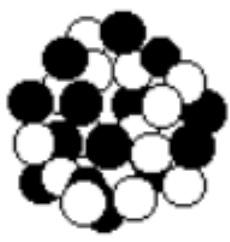

$\mathrm{Ni}-60$

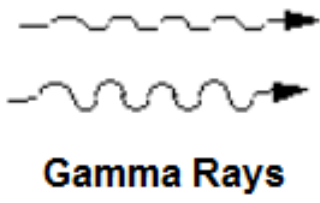

Gamma Rays

Figure 11. Gamma ray radiation [99]

Studies on the interaction of high energy radiation with polymers have attracted the attention of many researchers. This is due to the fact that high-energy radiation can induce both chain scission and/or crosslinking [100]. The efficiency of these two types of reactions depends mainly on polymer structure and irradiation atmosphere. However, dose rate, types of radiation source and temperature during irradiation can influence the reaction rates [101]. For some applications radiation degradation can be controlled and devoted to achieve a specific property [100]. Degradation, in broad terms, usually involves chemical modification of the polymer by its environment; modification that is often (but not always) detrimental to the performance of the polymeric material. Although the chemical change of a polymer is frequently destructive, for some applications degradation can be controlled and encouraged to achieve a specific property. In this regard, different vinyl monomers have been grafted onto gamma irradiated wool fabric to improve some favorable properties such as dyeability, and moisture regain. These studies have been based on the formation of stable peroxides on wool, upon irradiation, which are thermally decomposed to initiate polymerization [102].

Gamma rays are ionizing radiations that interact with the material by colliding with the electrons in the shells of atoms. They lose their energy slowly in material being able to travel through significant distances before stopping. The free radicals formed are extremely reactive, and they will combine with the material in their vicinity. The irradiated modified fabrics can allow: more dye or pigment to be fixed, producing deeper shades and more rapid fixation of dyes at low temperature [32]. In literature it is stated that two kinds of effects might occur in parallel in wool during the irradiation. The first effect as manifests as an evident decrease in dye accessibility at lower doses may not be altogether independent of crosslinking. On the other hand, the remarkable increase in the uptake at higher doses seems to be associated with strong structural damage of fibers. It is interesting to note that the increase in accessibility to dyes of the highly irradiated fibers is so great that the bilateral structure is hardly visualized by the partial staining. Thus the cross-sections of fibers irradiated with a dose of $10^{8}$ roentgens are stained uniformly in dark tone even under the condition which does not give rise to the staining of unirradiated fibers [103]. In literature there 
are limited studies related to the effect of gamma irradiation treatment on dyeability of proteinous fibers. Some of them are summarized below.

Horio et al. (1962) investigated the effect of irradiation on dyeing property of wool fiber. It was found that the dyeing property of wool fiber was greatly affected by irradiation even at low doses where any changes in mechanical properties were not noticeable. The rate of dye absorption was strongly depressed by irradiation with Co-60 gamma radiation of low doses from $10^{3}$ to $10^{5}$ roentgens. Two dyestuffs, C.I. Acid Red 44 and C. I. Acid Green 28 were used. The dye absorption was strikingly suppressed at the range of doses from $10^{3}$ to $10^{5}$ roentgens, but fibers regain dye accessibility at higher doses [103].

Beevers and McLaren (1974) have been found that small doses of gamma radiation (0.5-10 Mrad) produce marked effects on some physical properties of wool. The results indicate that even small doses of gamma radiation break sufficient covalent bonds to make the crosslinked peptide chain structure more susceptible to the action of swelling and disordering agents. These small radiation-induced changes can be expected to affect properties of wool significantly in absorption and penetration processes, such as those involved in dyeing, chemical modification, and grafting treatments of wool [104].

Millington(2000) investigated the effects of $\gamma$-radiation $\left({ }^{60} \mathrm{Co}\right)$ on some chemical and physical properties of wool keratin and compared and contrasted with the effects of ultraviolet radiation in the UVC (200-280 $\mathrm{nm}$ ) region. The effect of UVC doses up to $25 \mathrm{~J} / \mathrm{cm}^{2}$ on fabric strength was found to be small (5\%), whereas $\gamma$-irradiated wool experienced strength reductions of $15 \%$ at doses over $100 \mathrm{kGy}$. Color changes following UVC and $\gamma$-irradiation were quite different: UVC wool was initially green changing to yellow under ambient conditions, $\gamma$-treated wool became pink-red at doses 25-250 kGy, and yellow at higher doses. The chromophores produced by UVC were easily removed by oxidative bleaching with hydrogen peroxide, whereas $\gamma$-treated wool remained yellow even at relatively low doses (25-50 kGy). This has implications for the use of $\gamma$-radiation as a means of sterilising wool for compliance with quarantine regulations. The effects of the two forms of radiation on the natural fluorescence of wool, permanent setting, printing properties and the epicuticle layer were also described [105].

\section{Laser technology}

In the last decade, considerable effort has been made in developing surface treatments such as UV irradiation, plasma, electron beam and ion beam to modify the properties of textile materials. Laser modification on material surface is one of the most studied technologies [106]. A laser is a device that emits light (electromagnetic radiation) through a process of optical amplification based on the stimulated emission of photons. The term "laser" originated as an acronym for "Light Amplification by Stimulated Emission of Radiation" [107]. Laser processing as a new processing method, with its processing of accurate, fast, easy, automatization, in leather, textile and garment industry increasingly widely used [108]. 
Laser technology has been widely used in surface modification of polymers [109]. Since the late 90s, different types of commercial lasers are available for surface modification of materials [110]. While most of the efforts in developing surface treatments have been made using UV laser, infra-red lasers, like $\mathrm{CO}_{2}$ appear to be less concerning [109]. Adequate power levels for a specific application are very important in surface modification processes, because an excessive amount of energy can damage the polymers. Infra-red lasers like $\mathrm{CO}_{2}$ are the most powerful lasers; with no suitable power level, severe thermal damage can be resulted. However, this short coming can be overcome by the use of pulsed-mode $\mathrm{CO}_{2}$ lasers, which are easier to control than lasers operating in the continuous wave mode [110]. Excimer lasers, which are a form of ultraviolet lasers [111], are a special sort of gas laser powered by an electric discharge in which the lasing medium is an excimer, or more precisely an exciplex in existing designs. These are molecules which can only exist with one atom in an excited electronic state. Once the molecule transfers its excitation energy to a photon, therefore, its atoms are no longer bound to each other and the molecule disintegrates. This drastically reduces the population of the lower energy state thus greatly facilitating a population inversion. Excimers currently used are all noble gas compounds; noble gasses are chemically inert and can only form compounds while in an excited state. Excimer lasers typically operate at ultraviolet wavelengths [107].

It has been shown that materials like polymers, woods, metals, semiconductors, dielectrics and quartz modified by laser irradiation often exhibit physical and chemical changes in the material's surface [106]. Physical modifications occur in the form of a certain, regular surface structure of the irradiated sites. The high energy input of the excimer radiation into the polymer might also give rise to chemical changes of the surface [112]. In the case of polymers, some well-oriented structure of grooves or ripple structures with dimensions in the range of micrometer are developed on surface with irradiation fluence above the so-called ablation threshold. The laser irradiation of highly absorbing polymers can generate characteristic modifications of the surface morphology. The physical and chemical properties are also affected after laser irradiation. Hence, it is reasonable to believe that such surface modification of a polymer may have an important impact on its textile properties [106].

The possible applications of laser technology in the textile industry include removal of indigo dye of denim, heating threads, creating patterns on textiles to change their dyeability, producing surface roughness, welding, cutting textile webs. Laser irradiation on polymer surface is used to generate a modified surface morphology. The smooth surface of polymers is modified by this technique to a regular, roll-like structure that can cause adhesion of particles and coating, wetting properties and optical appearance [113].

Laser technology can also be used for improving dyeability since it is well known that the UV output from excimer lasers can modify the surface of synthetic fibers. But the use of laser energy in textile treatment is still uncommon and is generally limited with denim garment finishing [114]. Although there are many studies in the literature related to the investigation of the effect of laser treatment on dyeability of many fiber types, there is still no study carried out on wool. But, by taking into consideration that the chemical structure and dyeing property of proteinous fibers is similar to polyamide, in the light of the studies 
carried out on polyamide [114, 115], it can be said that dyeability of proteinous fibers with anionic dyes such as acid and reactive dyes may increase due to the decrease in the crystallinity and increase in free amino groups of the fiber.

\section{Microwave technology}

Microwaves (MW) which have broad frequency spectrum are electromagnetic waves that are used in radio, TV and radar technology [116]. MWs are radio waves with wavelengths ranging from as long as one meter to as short as one millimeter, or equivalently, with frequencies between $300 \mathrm{MHz}(0.3 \mathrm{GHz})$ and $300 \mathrm{GHz}$ [117].

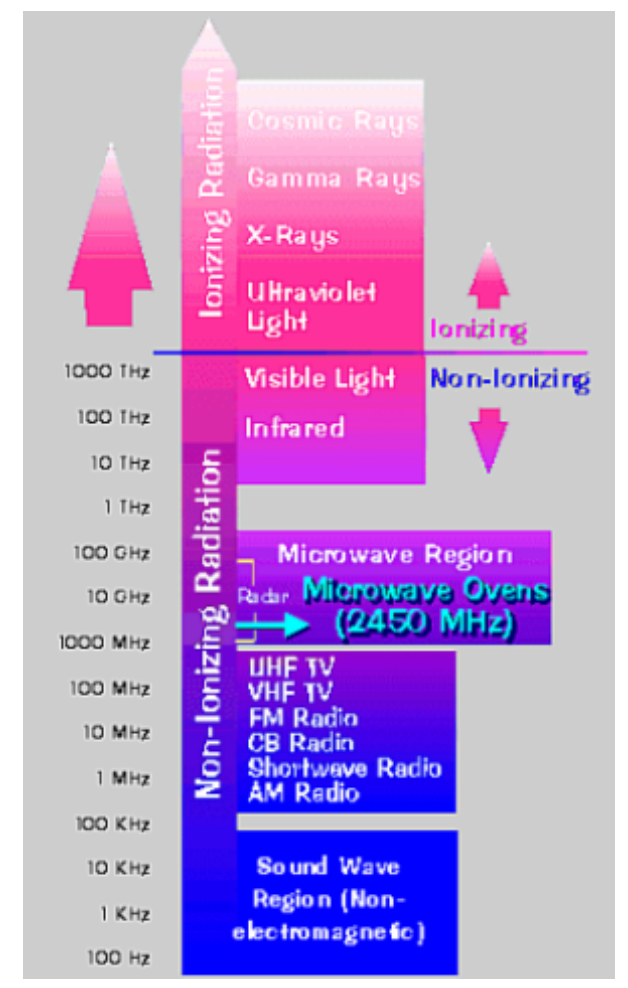

Figure 12. Frequency spectrum [118]

The term "microwave" denotes the techniques and concepts used as well as a range of frequencies. Microwaves travel in matter in the same manner as light waves: they are reflected by metals, absorbed by some dielectric materials and transmitted without significant losses through other materials. For example, water, carbon, foods with a high water, some organic solvents are good microwave absorbers whereas ceramics, quartz glass and most thermo- 
plastic materials absorb microwaves slightly [119]. Electromagnetic waves can be absorbed and be left as energy units called photon. The energy carried by photon is depended on the wavelength and the frequency of radiation. Energy of MW photons is $0.125 \mathrm{~kJ} / \mathrm{mol}$. This value is very low considering the necessary energy for chemical bonds. Therefore MW rays can not affect the molecular structure of the material directly and change the electronic structures of atoms [116].

Microwave-promoted organic reactions are known as environmentally benign methods that can accelerate a great number of chemical processes. In particular, the reaction time and energy input are supposed to be mostly reduced in the reactions that are run for a long time at high temperatures under conventional conditions [120]. Reactions conducted through microwaves are cleaner and more environmentally friendly than conventional heating methods [121].

The use of microwave radiation as a method of heating is over five decades old. Microwave technology originated in 1946, when Dr. Percy Le Baron Spencer, while conducting laboratory tests for a new vacuum tube called a magnetron, accidentally discovered that a candy bar in his pocket melted on exposure to microwave radiation. Dr. Spencer developed the idea further and established that microwaves could be used as a method of heating. Subsequently, he designed the first microwave oven for domestic use in 1947. Since then, the development of microwave radiation as a source of heating has been very gradual [121].

Microwave heating occurs on a molecular level as opposed to relying on convection currents and thermal conductivity when using conventional heating methods. This offers an explanation as to why microwave reactions are so much faster [122]. The fundamental mechanism of microwave heating involves agitation of polar molecules or ions that oscillate under the effect of an oscillating electric or magnetic field. In the presence of an oscillating field, particles try to orient themselves or be in phase with the field. However, the motion of these particles is restricted by resisting forces (inter-particle interaction and electric resistance), which restrict the motion of particles and generate random motion, producing heat [121]. Microwave (MW) heat systems consists of three main units; magnetron, waveguide and applicator. Magnetron is used as a microwave energy source in industrial and domestic type of microwave ovens. One of the oscillator tube, magnetron consists of two main parts as anode - cathode, and it converts the continuous current - electrical energy to MW energy. Circulator transmits approximately all of the waves that are sent from magnetron and shunts transmitted waves to water burden. Thus magnetron is protected. Electromagnetic waves are transmitting to the applicator by waveguides. Applicators are parts of the matter MW applied on. MW energy produced in generator is affected directly on the material in applicators in MW heating systems. Type of applicators used in practice can be divided into three groups as multi-mode (using $80 \%$ of the industrial systems), single-mode and near field MW applicators [116].

Since the beginning of the twentieth century MW technology has made significant contributions to scientific and technological developments. Also due to its initial intend to be used in telecommunications, very important progresses have been made in this area. Nevertheless from the second half of twentieth century, MW energy is finding increased number of appli- 
cation area in other industrial processes and these applications are surpassing telecommunication applications [116].

In textile processing it is necessary to apply heat as in dye fixation, heat setting or drying the product. Heat can be transferred to the material by radiation, conduction and convection. These three ways of transferring can be used either separately or in combination. The saving of time and energy is of immediate interest to the textile industry. The introduction of new techniques which will allow less energy to be used: is a highly important area of activity to consider. The textile industry has investigated many uses for microwave energy such as heating, drying, dye fixation, printing and curing of resin finished fabrics. In 1966, Ciba-Geigy obtained one of the earliest patents for using microwave heating in dyeing and printing fibrous material with reactive dyes. Since then many authors have investigated the feasibility of using microwaves for a variety of dyeing and finishing processes [123]. Although many studies have focused on investigating the feasibility of using microwaves to dye polyester fibers with disperse dyes, researches related to the use of microwave heating in dyeing of proteinous fibers are very limited.

Delaney and Seltzer (1972) used microwave heating for fixation of pad-dyeings on wool and they demonstrated the feasibility of applying certain reactive dyes to wool in fixation times of 30-60 s [124].

Zhao and He (2011) treated the wool fabric with microwave irradiation at different conditions and then studied for its physical and chemical properties using a variety of techniques, such as Fourier transform infrared spectroscopy, X-ray diffraction, and scanning electron. It was found that microwave irradiation of wool fabric significantly improved its dyeability. It was stated that this could be due to the change in wool surface morphological structure under microwave irradiation which implied that the barrier effect in wool dyeing was diminished. Although the breaking strength of the treated wool fabrics also improved with microwave irradiation, the chemical structure and crystallinity did not show any significant change [125].

In literature it was stated that dyeing time of mohair could be drastically reduced from the conventional 90 minutes to 35 minutes using the radio frequency technique, only 5 minutes of the 35 minutes representing actual exposure to the radio frequency field. An estimated saving of some $80 \%$ in dyeing energy costs could be achieved. Furthermore, dye fixation improved slightly from $93 \%$ to $96 \%$. Turpie quoted unpublished data in which radio-frequency dyeing of tops produced better luster and enabled higher maximum spinning speeds than did conventional dyeing of mohair. Smith, claimed advantages of radio-frequency dyeing and bleaching, - for example, reduced chemical damage because of a shorter exposure to $100^{\circ} \mathrm{C}$; and reduced energy, water and effluent costs [126].

\section{E-beam irradiation technology}

Radiation processing has been increasingly applied in industries to improve the quality of products, efficiency, energy saving and to manufacture products with unique properties 
[127]. An irradiation can induce chemical reactions at any temperature in the solid, liquid and gas phase without any catalyst; it is a safe method that could protect the environment against pollution; radiation process could reduce curing time and energy saving; it could treat a large and thick three-dimensional fabrics that need not consider of the shape of the samples [128].

Physical techniques for activating fiber molecules in the absence of solvent for producing functional textiles are becoming increasingly attractive also from an ecological viewpoint. Among them, electron beam processing is particularly interesting as it offers the possibility to treat the materials without solvent, at normal temperature and pressure [129]. Whilst the energy of the electrons in gas discharge plasmas is typically in the range of 1-10 electron volt $(\mathrm{eV})$, electron-beam (E-beam) accelerators generate electrons with a much higher energy, generally $300 \mathrm{keV}$ to $12 \mathrm{MeV}$. These electrons may be used to modify polymer materials through direct electron-to-electron interactions. These interactions can create active species such as radicals, so there are different possible outcomes from the electron-beam irradiation of polymer materials, on the basis of the chosen operating conditions [130].

The formation of active sites on the polymer backbone can be carried out by several methods such as plasma treatment, ultraviolet (UV) light radiation, decomposition of chemical initiator and high-energy radiation [131]. At present, the most common radiation types in industrial use are gamma and e-beam. E-beam machines play a significant role in the processing of polymeric materials; a number of different machine designs and different energies are available. Industrial e-beam accelerators with energies in the $150-300 \mathrm{keV}$ range are in use in applications where low penetration is needed, such as curing of surface coatings. Accelerators operating in the $1.5 \mathrm{MeV}$ range are used where more penetration is needed. Ebeam machines have high-dose rate and therefore short processing times. While they have limited penetration compared with gamma, they conversely have good utilization of energy because it can all be absorbed by the sample irradiated [132].

New radiation processing applications involving ion-beam treatment of polymers offer exciting prospects for future commercialization, and are under active investigation in many research laboratories. Much of the work has involved the irradiation of non-polar polyolefins (PE, PS, PP, etc.) as a means of inducing polar groups at surfaces, in order to enhance such properties as printability, wetability and exc. [132]. Studies related to the e-beam irradiation of proteinous fibers are limited.

Fatarella et al.(2010) wanted to clarify whether fiber surface treatments such as plasma and ebeam could affect the effectiveness of a TGase treatment by improving the accessibility of target amino acids in wool to the enzyme or improving the penetration of the enzyme into the wool fiber cortex, thus accessing more sites for reaction. Plasma treatments with different non-polymerizing gases (oxygen, air and nitrogen) and e-beam irradiation in air or nitrogen atmosphere were assessed as possible pretreatments to non-proteolytic enzymatic processes (such as TGase) to improve the accessibility of target groups in the wool proteins to the enzymes. Only limited inhibition and/or inactivation of the transglutaminase enzyme was found after treatment with plasma and e-beam, suggesting such treatments could be used as a preparative treatment prior to the application of the enzyme. In contrast, by in- 
creasing the energy of the electrons in e-beam treatments no significant superficial modifications were observed. In fact, they promoted the cleavage of high-energy bond, such as S-S linkage, by enhancing depolymerization reaction [130].

\section{Ion implantation technology}

It has been approximately 50 years since researchers first began exposing polymeric materials to ionizing radiation, and reporting the occurrence of cross-linking and other useful effects. Innovation in this field has by no means ended; important new products made possible through radiation technology continue to enter the marketplace, and exciting new innovations in the application of radiation to macromolecular materials are under exploration at research institutions around the world [132]. Ionizing radiation may modify physical, chemical and biological properties of materials [133]. Some of the surface characteristics being successfully manipulated by radiation grafting include: chemical resistance, wetability, biocompatibility, dyeability of fabrics, and antistatic properties [132].

Ion implantation is an innovative production technique with which the surface properties of inert materials can be changed easily. It shows distinct advantages because it is environmentally friendly. Ion implantation can be used to induce both surface modifications and bulk property enhancements of textile materials, resulting in improvements to textile products ranging from conventional fabrics to advanced composites. Ion implantation was first done by Rutherford in 1906, when he bombarded aluminum foil with helium ions. Ion implantation has been applied to metals, ceramics, plastics, and polymers [134].

Even though ion implantation is relatively complex in terms of the equipment required, it is a relatively simple process. Ion implantation consists of basically two steps: form plasma of the desired material, and either extract the positive ions from the plasma and accelerate them toward the target, or find a means of making the surface to be implanted the negative electrode of a high voltage system [135]. There are three methods commonly used for ion implantation. They differ in the way in which they either form the plasma or make the surface to be implanted the negative electrode. These methods are mass-analyzed ion implantation, direct ion implantation and plasma source ion implantation [134].

In mass-analyzed ion implantation, the plasma that is formed in the ion source is not pure; it contains materials that one does not wish to implant. Thus, these contaminants must be separated from the plasma. To perform this separation, the plasma source is placed at a high voltage and the part to be implanted is placed at ground. This produces a situation where the target is at a negative potential with respect to the plasma source. A negative electrode then extracts the ions from the source. The ions are then accelerated by a high voltage source to the target. Between the ion source and the target there is a large magnet, with magnetic field perpendicular to the direction of ion motion. Ions passing through this magnetic field are bent by the magnetic field. The amount of bending depends on the ion material being implanted and the strength of the magnet [135]. 
Direct ion implantation eliminates the need for the current limiting magnet found in mass-analyzed ion implantation by using an ion source that produces a plasma and ion beam of just the desired material. In direct ion implantation, the plasma is formed in the ion source and the ions extracted at high energies in a wide beam, passing through a valve directly into the end station, where the ion implant parts within the target area. In such a case, the beam current density can be high (10-50 mA), costs are greatly reduced, and relatively high throughput processing is possible [135].

It is difficult in practice to treat uniformly three-dimensional objects such as sockets in artificial hip joints, without using sophisticated manipulating devices. Recently, however, an innovative hybrid technology, plasma source ion implantation has been developed, which can, to a large extent, address the problems with conventional ion implantation of components with complex shapes [136]. In plasma source ion implantation (sometimes referred to as plasma ion immersion), the plasma source floods the chamber of the end station with plasma. Ions are extracted from the plasma and directed to the surface of the part being ion implanted by biasing the part to very high negative voltages using a pulsed, negative high voltage power supply [135].

One of the most recent ion implantation techniques is metal vapor vacuum arc (MEVVA), a type of direct ion implantation. In the mid-1980s, Brown et al. at Lawrence Berkeley Laboratory developed a new type of metal ion source, namely the MEVVA ion source. The MEVVA source makes use of the principle of vacuum arc discharge between the cathode and the anode to create dense plasma from which an intense beam of metal ions of the cathode material is extracted. This metal ion source operates in a pulse mode [134].

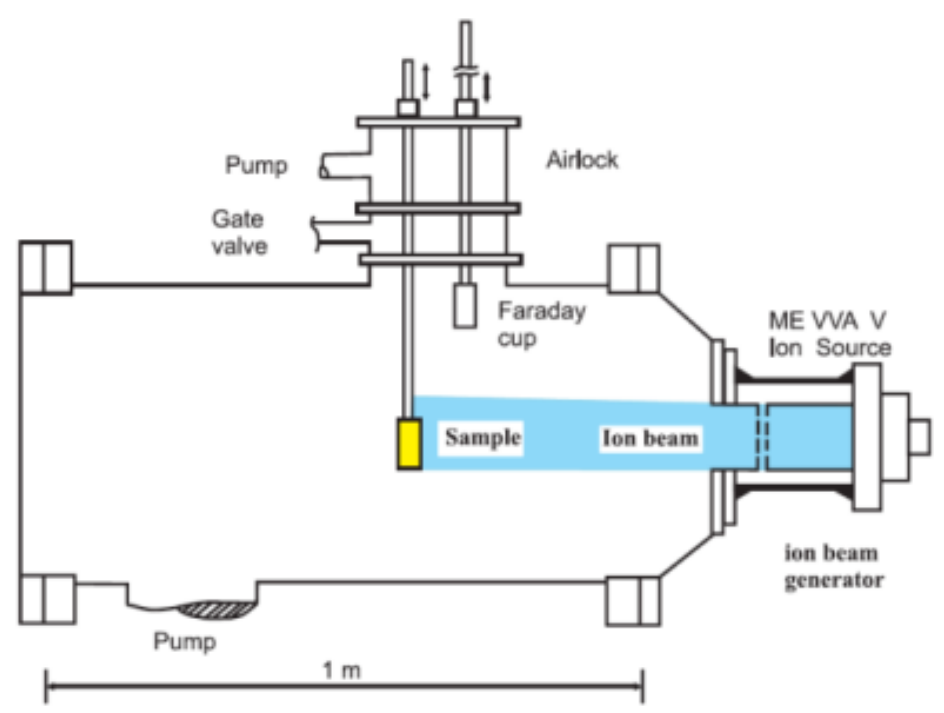

Figure 13. MEVVA ion implanter [134] 
Many techniques have been applied to produce the great potential of ion beam modification technology. It desired surface modifications, ranging from conventional flame treatments, "wet" chemical treatments, and electrical treatments (such as corona discharge), to modern plasma treatments and particle beam irradiation (electrons, ions, neutrons and photons) techniques. Among them, particle beam techniques are particularly attractive owing to their flexibility, effectiveness, and environmentally friendly nature compared with conventional techniques. Also, in the domain of particle beam techniques, the ion beam has proven more effective in modifying polymer surfaces than UV-light, c-ray, X-ray and electron beams. This is because energetic ions have a higher cross-section for ionization and larger linear energy transfer $\left(\mathrm{LET}, \mathrm{eV} \mathrm{nm}^{-1}\right.$ ) than these conventional radiation types of comparable energy owing to their deeper range [136].

Numerous papers have appeared in recent years describing surface treatment using ions. Surface modification with ions typically involves fluencies of $\sim 10^{9}$ to $10^{14}$ ions $/ \mathrm{cm}^{2}$ or in some cases, $10^{15}$ ions $/ \mathrm{cm}^{2}$; higher fluencies may result in destruction of polymer, generally through carbonization. Many different ions have been employed for irradiating polymers, ranging from hydrogen and helium ions up to ions of heavy elements such as gold or uranium [132].

\section{Supercritical carbondioxide technology}

The enhanced solvent properties provided by supercritical fluids (SCFs) are by no means new. In fact, the various phenomena attributed to SCFs have been known for hundreds of years [137]. However, textile dyeing, using supercritical carbon dioxide as dye solvent, has been developed for the last two decades since it potentially overcomes all the economical and ecological disadvantages derived from the conventional water dyeing process [138]. Supercritical fluids are characterized by a very high solute diffusivity and low viscosity. Consequently, in supercritical fluids all the transport processes are much more rapid. Dyeing in supercritical carbondioxide, for example, entirely avoids the use of water, and consequently there is no possibility of pollution. No auxiliary agents are used and residual dye can be recovered in a reusable form [139].

A supercritical fluid can be defined as a substance above its critical temperature and pressure. Under this condition the fluid has unique properties, in that it does not condense or evaporate to form a liquid or a gas [140]. Supercritical fluids exhibit gas-like viscosities and diffusivities and liquid-like densities [120]. Although a number of substances are useful as supercritical fluids, carbon dioxide has been the most widely used [140], as the critical temperature and pressure are easier to achieve than that of other substances [141]. Supercritical $\mathrm{CO}_{2}$ is a dyeing medium which is a potential alternative to water as it is inherently nontoxic, inexpensive, and nonflammable, it can be recycled, it has easily accessible critical conditions [142]. The critical point for carbon dioxide occurs at a pressure of $73.8 \mathrm{bar}$ and a temperature of $31.1^{\circ} \mathrm{C} . \mathrm{ScCO}_{2}$ represent a potentially unique media for either transporting chemical into or out of a polymeric substrate, because of their thermo-physical and transport properties. 
The phase diagram of carbon dioxide shown in Fig. 14 represents the interfaces between phases; at the triple point all three phases may coexist. Above the triple point, an increase in temperature drives liquid into the vapor phase, while an increase in pressure drives vapor back to liquid [120]. Above the critical point of carbon dioxide, it retains the free mobility of the gaseous state, but with the increasing pressure its density will increase towards that of a liquid. Solvating power is proportional to density, whilst viscosity remains comparable with that of a normal gas, so the "fluid" has remarkable penetration properties [143].

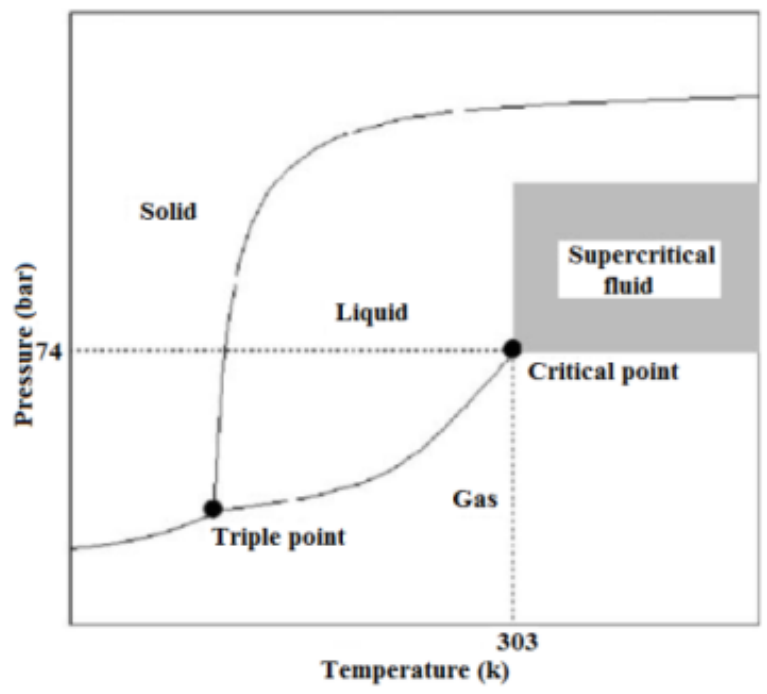

Figure 14. Phase diagram of carbon dioxide [120]

In the dyeing field, Schollmeyer and co-workers, among others, have demonstrated that both synthetic and natural fibres can be dyed with disperse and reactive disperse dyes in supercritical carbondioxide. However, the dyeing of natural fibres with water soluble dyes in supercritical carbondioxide has not yet been successful, since dyes such as reactive, acid and basic dyes have little solubility in this medium due to their high polarity [144]. One approach to this problem was undertaken by Gebert et al. who examined wool and cotton fibers after attempting to open the fiber surface with a swelling auxiliary so that dye molecules could be readily trapped in the fiber [145].

In natural textiles, the dye molecules can be fixed by either physical (e.g. Van der Waals) or chemical (e.g. covalent) bonds. Since the dyes used in a ScCO2-dyeing process are non-polar and natural fibres are polar, the affinity between dyes and textiles is low so physical bonds are weak. Therefore, a dyeing process must be developed for dyeing natural textiles in $\mathrm{ScCO} 2$ with reactive dyes that create covalent dye-textile bonds. So far, several reactive dyes known from conventional dyeing in water have been investigated in $\mathrm{ScCO}$ :

- vinylsulphone dyes have been successfully used for silk and wool, 
- 2-bromoacrylamide dyes have been successful in dyeing wool and cotton,

- dichlorotriazine dyes have been tested on silk and cotton but showed insufficient fixation [146].

Guzel and Akgerman (2000) dyed the wool fibers with three mordant dyes dissolved in supercritical carbon dioxide. Wool fibers were mordanted with five different metal ions ( $\mathrm{Cr}(\mathrm{III})$, $\mathrm{Al}(\mathrm{III}), \mathrm{Fe}(\mathrm{II}), \mathrm{Cu}(\mathrm{II})$ and $\mathrm{Sn}(\mathrm{II}))$ using conventional techniques and dyed at $333-353^{\circ} \mathrm{K}$ temperature and at 150-230 atm pressure. According to the experimental results it was found that dyed materials had excellent wash fastness properties [147].

For water-soluble dyes, attempts were made to dye natural fibers using reverse micelle technique (Fig. 15) in which ionic dye, solubilized in the water-pool, passes into the fiber together with a small amount of water immediately after contact with it. Satisfactory results were obtained for proteinous fibers [120].

Sawada et al. (2002) has developed a reverse micellar system in supercritical carbon dioxide as a dyeing medium. Water-soluble dyes such as reactive dyes and acid dyes could be sufficiently solubilised in the interior of a specially constituted reverse micelle. Protein fabrics, silk and wool, were satisfactorily dyed even in deep shades with conventional acid dyes without any special pretreatment. Compared to previously proposed supercritical dyeing methods, dyeing of fabrics with this system could be performed at low temperatures and pressures in a short time [148].

Jun et al. (2004) investigated the dyeing of wool fabrics with conventional acid dyes in a supercritical $\mathrm{CO}_{2}$ using a reverse micellar system. A reverse micelle composed of perfluoro 2,5,8,11-tetramethyl-3,6,9,12-tetraoxapentadecanoic acid ammonium salt/ $\mathrm{CO}_{2} /$ water had a high potential to solubilize conventional acid dyes and to dye wool fabrics in this system. It was found that dyeability of the acid dye on wool in this system take no influence of the density of $\mathrm{CO}_{2}$. On the other hand, variation of dyeing temperature resulted in the remarkable differences of the dyeability of the acid dye on wool even though the solubility of dye in the system was not varied by the variation of temperature [149]
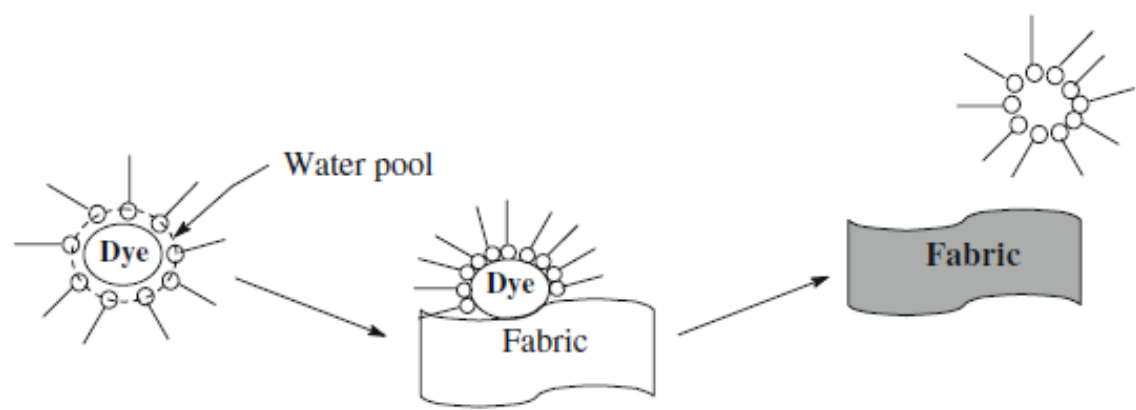

Figure 15. Dyeing of natural fibers using reverse micelle [120] 
Jun et al. (2005) investigated the phase behavior of a cationic perfluoropolyether surfactant in supercritical carbon dioxide and its ability to solubilise ionic dyes. This cationic surfactant was found to dissolve satisfactorily in supercritical carbon dioxide and was able to form micellar aggregates incorporating a small amount of water in their interior. Conventional anionic dyes such as acid and reactive dyes were solubilised satisfactorily in the cationic surfactant/water/supercritical carbon dioxide system. The surfactant was more effective in this respect than its anionic analogue [144].

Schmidt et al. (2007) dyed various fibers, among which wool and silk also exist, with C.I. Disperse Yellow 23 modified with 2-bromoacrylic acid and 1,3,5-trichloro-2,4,6-triazine as reactive groups in supercritical carbon dioxide. It was found that on wool and silk, the color depth was higher than on cotton and the wash, rub and light fastness of all dyeings was between 4 and 5 [150].

\section{Conclusions}

Textile dyeing is the most remarkable process among the wet treatments in textile industry in terms of energy and water consumption and effluent load. In last two decades increased laws related to the environment and competitive market conditions required some new processes to be found in textile dyeing field. This situation increased the interest of the usage of new technologies such as ultrasound, ultraviolet, ozone, plasma, gamma irradiation, laser, microwave, e-beam irradiation, ion implantation, and supercritical carbondioxide in textile industry. These new technologies provide not only decrease in time, energy, and chemical consumption, but also decrease in effluent load. So that all of these new technologies considered to be very interesting future oriented processes because of being environmentally friendly. Although it was proven with many researches that most of these technologies are successful at laboratory scale, there is still need to integrate them into industrial applications. There is no doubt that in future these new technologies will find wide range of applications when their disadvantages (to be expensive, not possible to be used for all fiber types and exc.) will be eliminated.

\section{Author details}

Riza Atav

Namık Kemal University, Textile Engineering Department, Turkey

\section{References}

[1] Lewis, D.M., 1992, Wool Dyeing, Society of Dyers and Colorists 
[2] Jocic, D., Vilchez, S., Topalovic, T., Molina, R., Navarro, A., Jovancic, P., Julia, M.R. and Erra, P., 2005, Effect of Low-Temperature Plasma and Chitosan Treatment on Wool Dyeing with Acid Red 27, Journal of Applied Polymer Science, 97 (6), 22042214 .

[3] Molina, R., Erra, P., Julia, L., and Bertran, E., 2003, Free Radical Formation in Wool Fibers Treated by Low Temperature Plasma, Textile Research Journal, 73, 955-959p.

[4] Onar, N. and Sarışık M., January-March 2005, Use of Enzymes and Chitosan Biopolymer in Wool Dyeing, Fibers \& Textiles in Eastern Europe, 13 (1), 54-59p.

[5] Cardamone, J. M. and Damert, W.C., 2006, Low-Temperature Dyeing of Wool Processed for Shrinkage Control, Textile Research Journal, 76 (1), 78-85p.

[6] Kongkachuichay, P., Shitangkoon, A. and Chinwongamorn, N., 2002, Studies on Dyeing of Silk Yarn with Lac Dye: Effects of Mordants and Dyeing Conditions, Science Asia, 28, 161-166p.

[7] Luo, J. and Cao, J., 1997, Low-Temperature Dyeing of Real Silk Fabrics with Liquid Sulphur Dyes, JSDC, 113, 67-69p.

[8] Leksophee, T., Supansomboon, S. and Sombatsompop, N., 2004, Effects of Crosslinking Agents, Dyeing Temperature, and $\mathrm{pH}$ on Mechanical Performance and Whiteness of Silk Fabric, Journal of Applied Polymer Science, 91, 1000-1007p.

[9] Tsukada, M., Katoh, H., Wilson, D., Shin, B., Arai, T., Murakami, R. and Freddi, G., 2002, Production of Antimicrobially Active Silk Proteins by Use of Metal-Containing Dyestuffs, Journal of Applied Polymer Science, 86, 1181-1188p.

[10] Shao, J., Liua, J. and Carr, C.M., 2001, Investigation into The Synergistic Effect Between UV/Ozone Exposure and Peroxide Pad-Batch Bleaching on The Printability of Wool, Coloration Technology, 117 (5), 270-275p.

[11] Kamel, M.M., El-Shistawy, R.M., Hana, H.L. and Ahmed, N.S.E., 2003, Ultrasonic-Assisted Dyeing: I. Nylon Dyeability with Reactive Dyes, Polymer International, 52 (3), 373-380p.

[12] Akalın, M., Merdan, N., Kocak, D. and Usta, I, 2004, Effects of Ultrasonic Energy on The Wash Fastness of Reactive Dyes, Ultrasonics, 42, 161-164p.

[13] Vajnhandl, S. and Le Marechal, A.M., 2005, Ultrasound in Textile Dyeing and The Decoloration/Mineralization of Textile Dyes, Dyes and Pigments, 65 (2), 89-101p.

[14] Boz, S., 2008, Ultrasonik Enerjinin Konfeksiyon Sanayiinde Kullanımının İncelenmesi, Master Thesis Ege University Textile Engineering Department

[15] Moholkar, V.S., Nierstrasz, V.A. and Warmoeskerken, M.M.C.G., 2003, Intensification of Mass Transfer in Wet Textile Processes by Power Ultrasound, AUTEX Research Journal, 3 (3), 129-138p. 
[16] Jung, C., Budesa, B., Fässler, F., Uehlinger, R., Müller, T. and Wild, M., Effect of Cavitation in Ultrasound Assisted Cleaning of Medical Devices, http://www.kks-ultraschall.ch/assets/files/news/effect-of-caviation-ultrasound.pdf

[17] Kamel, M.M., El-Shishtawy, R.M., Yussef, B.M. and Mashaly, H., 2005, Ultrasonic assisted dyeing III. Dyeing of wool with lac as a natural dye, Dyes and Pigments, 65 (2), 103-110p.

[18] Moholkar, V.S., Rekveld, S. and Warmoeskerken, M.M.C.G., 2000, Modeling of The Acoustic Pressure Fields and The Distribution of The Cavitation Phenomena in A Dual Frequency Sonic Processor, Ultrasonics, 38, 666-670p.

[19] Santos, H.M., Lodeiro, C., Luis, J.L. and Martinez, C., The Power of Ultrasound, http://www.wiley-vch.de/books/sample/3527319344_c01.pdf

[20] Vouters, M., Rumeau, P., Tierce, P. and Costes, S., 2004, Ultrasounds: An Industrial Solution to Optimize Costs, Environmental Requests and Quality for Textile Finishing, Ultrasonics Sonochemistry, 11, 33-38p.

[21] http://www.ntcresearch.org/pdf-rpts/anrp98/c95-g13.pdf, 2008

[22] Ferrero, F. and Periolatto, M., 2012, Ultrasound for Low Temperature Dyeing of Wool with Acid Dye, Ultrasonics Sonochemistry, 19, 601-606

[23] hukla, S.R. and Mathur, M.R., 1995, Low-Temperature Ultrasonic Dyeing of Silk, Journal of the Society of Dyers and Colorists, 111, 342-5p.

[24] http://www.fiber2fashion.com, 2008

[25] Battu, A., Giansetti, M., Rovero, G. and Sicardi, S., 2010, Intensification of Wet Textile Processing By Ultrasound Application, Proceedings of the 22nd IFATCC International Congress, Stresa, Italy

[26] Yukseloğlu, S.M. and Bolat, N., 2010, The Use of Conventional and Ultrasonic Energy in Dyeing of 100\% Wool Woven Fabrics, Tekstil ve Konfeksiyon, 2, 162-167p.

[27] McNeil, S.J. and McCall, R.A., 2011, Ultrasound for Wool Dyeing and Finishing, U1trasonics Sonochemistry, 18, 401-406

[28] Atav, R., Yurdakul, A., 8-10 June-2011, The Use of Ultrasound in Dyeing of Mohair Fibers, 11th World Textile Conference AUTEX, Moulhouse-France, Book of Abstracts, 277-280p.

[29] Srikanth, B., The Basic Benefits of Ultraviolet Technology, http://aquvair.com/Basic \%20Benefits\%20of\%20UV\%20-WCP\%20Reprint.pdf

[30] http://en.wikipedia.org/wiki/Electromagnetic_spectrum, 2012

[31] http://skincareclub.wordpress.com/2011/02/25/uva-uvb-uvc-rays/, 2012

[32] Bhatti, I.A., Adeel, S. and Abbas, M., Effect of Radiation on Textile Dyeing, http:// cdn.intechweb.org/pdfs/25003.pdf 
[33] http://www.epa.gov/sunwise/doc/uvradiation.html, 2012

[34] http://ec.europa.eu/health/opinions2/glossary/tuv/uv-radiation.htm, 2012

[35] http://www.google.com.tr/imgres?q=ultraviolet+spectrum\&hl=tr\&biw=1249\&bih=599\&tbm=isch\&tbnid=1xj5wLLo6i43HM:\&imgrefurl=http://www.uvlp.ca/\&docid=OAkRjqeFw_ZM9M\&imgurl=http://www.uvlp.ca/ images/uvspectrum.jpg\&w=450\&h=162\&ei=3vr7T9XoK8jatAaww8m_Aw\&zoom=1, 2012

[36] Treigiene, R. and Musnickas, J. R., 2008, Influence of UV Exposure on Properties of Wool Fiber Pretreated with Surfactants Solutions, Materials Science, 14 (1), 75-78p.

[37] Millington, K., 1998, Using Ultraviolet Radiation to Reduce Pilling of Knitted Wool and Cotton, Textile Research Journal, 68 (6), 413-421p.

[38] Millington, K. R., CSIRO Textile and Fiber Technology, UV Technology Applications in The Textile Industry, http://www.fiber2fashion.com/industry-article/pdffiles/uvtechnology-applications-in-the-textile-industry.pdf?PDFPTOKEN=73534d84ba5e495e4164c5a831509f62275d95dc\%7C1225281847

[39] El-Sayed, H. and El-Khatib, E., 2005, Modification of wool fabric using ecologically acceptable UV-assisted treatments, Journal of Chemical Technology and Biotechnology, 80 (10), 1111-1117p.

[40] Millington, K. R., 1998, The Use of Ultraviolet Radiation in an Adsorbable Organohalogen-Free Print Preparation for Wool and in Wool Dyeing: the Siroflash Process Journal of the Society of Dyers and Colorists, 114 (10), 286-292p.

[41] Millington, K. R., 1998, U.S.A. Patent, Application of UV surface treated in textile industry, Red Tech 98 North Americas: UNEB Conference Proceeding Chicago ILLINOIS America

[42] Xin, J.H., Zhu, R., Hua, J. and Shen, J., 2002, Surface Modification and Low Temperature Dyeing Properties of Wool Treated By UV Radiation, Coloration Technology, 118 (4), 169-173p.

[43] http://www.sfu.ca/ vwchu/projects/chemistryozone.pdf, 2012

[44] Polat, D., 2010, Catalytic Ozonation of Industrial Textile Wastewaters in A Three Phase Fluidized Bed Reactor, Master Thesis, The Graduate School of Natural Sciences of Middle East Technical University

[45] http://water.epa.gov/lawsregs/rulesregs/sdwa/mdbp/upload/ 2001_01_12_mdbp_alter_chapt_3.pdf, 2012

[46] Parmenter, K., 2004, Global Ozone Handbook Agriculture and Food Industries http:// www.chimia.it/pdf/Ozone\%20Handbook\%20-\%20Revised\%2003-11-05\%20Final.pdf

[47] Balousek, P.J., 1979, The Effects of Ozone Upon A Lignin-Related Model Compound Containing A $\beta$-Aryl Ether Linkage, PhD Thesis, Lawrence University 
[48] http://en.wikipedia.org/wiki/File:Ozone-1,3-dipole.png, 2012

[49] http://astrobioloblog.wordpress.com/2011/08/18/life-in-our-solar-system\%E2\%80\%93-earth/, 2012

[50] Iglesias, S.C., 2002, Degradation and Biodegradability Enhancement of Nitrobenzene and 2,4-Dichlorophenol By Means of Advanced Oxidation Processes Based on Ozone, Universitat de Barcelona, $\mathrm{PhD}$ thesis

[51] Prabaharan, M. and Rao, J.V., 2001, Study on Ozone Bleaching of Cotton Fabric-Process Optimisation, Dyeing and Finishing Properties, Coloration Technolgy, 117 (2), 98-103p.

[52] Song, S., Yao, J., He, Z., Qiu, J. and Chen, J., 2008, Effect of Operational Parameters on The Decolorization of C.I. Reactive Blue 19 in Aqueous Solution By Ozone-Enhanced Electrocoagulation, Journal of Hazardous Materials, 152, 204-210p.

[53] El-Zaher, N.A. and Micheal, M.N., 2002, Time Optimization of Ultraviolet-Ozone Pretreatment for Improving Wool Fabrics Properties, Journal of Applied Polymer Science, 85(7), 1469-1476p.

[54] Atav, R. and Yurdakul, A., 2011, Effect of Ozonation Process on the Dyeability of Mohair Fibers, Coloration Technology, 127(3), 159-166

[55] Wu, C.H. and Ng, H.Y., 2008, Degradation of C.I. Reactive Red 2 (RR2) Using OzoneBased Systems: Comparisons of Decolorization Efficiency and Power Consumption, Journal of Hazardous Materials, 152, 120-127p.

[56] Eren, H.A. and Aniş, P., 2006, Decolorisation of Textile Effluents by Ozonation, Uludağ University Journal of the Faculty of Engineering and Architecture, 11(1), 83-91p.

[57] Perincek, S., Bahtiyari, M.I., Körlü, A.E. and Duran, K., 2008, Ozone Treatment of Angora Rabbit Fiber, Journal of Cleaner Production, 16, 1900-1906p.

[58] Sargunamani, D. and Selvakumar, N., 2007, Effects of Ozone Treatment on The Properties of Raw And Degummed Tassar Silk Fabrics, Journal of Applied Polymer Science, 104 (1), 147-155p.

[59] Dereli Perincek, S., 2006, An investigation on The Applicability of Ultrasound, Ultraviolet, Ozone and Combination of These Technologies as A Pretreatment Process, Master Thesis, Ege Üniversitesi Fen Bilimleri Enstitüsü

[60] Micheal, M.N. and El-Zaher, N.A., 2003, Efficiency of Ultraviolet/Ozone Treatments in The Improvement of The Dyeability and Light Fastness Of Wool, Journal of Applied Polymer Science, 90 (13), 3668-3675p.

[61] Atav, R. and Yurdakul, A., 2010, Low Temperature Dyeing of Ozonated Angora Fibers, 10th World Textile Conference AUTEX, Vilnius-Litvania, Book of Abstracts, $16 \mathrm{p}$. 
[62] Sparavigna, A., Plasma Treatment Advantages for Textiles, http://arxiv.org/ftp/arxiv/ papers/0801/0801.3727.pdf

[63] Moore, R., Plasma Surface Functionalization of Textiles, http://www.acteco.org/Acteco/public/results/MOORE_IoN_March08.pdf

[64] http://www.britannica.com/EBchecked/media/148660/States-of-matter, 2012

[65] http://www.fiber2fashion.com/industry-article/17/1636/plasma-treatment-technology-for-textile-industry1.asp, 2012

[66] http://www-alt.igb.fraunhofer.de/www/gf/grenzflmem/schichten/en/TechTextile.en.html, 2012

[67] Shyam Sundar, P., Prabhu, K.H. and Karthikeyan, N.,2007, Fourth State Treatment for Textiles, The Indian Textile Journal, http://www.indiantextilejournal.com/articles/ FAdetails.asp?id=290

[68] Desai, A.A., 2008, Plasma Technology: A Review, The Indian Textile Journal http:// www.indiantextilejournal.com/articles/FAdetails.asp?id=775

[69] Buyle, G., 2009, Nanoscale Finishing of Textiles Via Plasma Treatment, Materials Technology, 24(1), 46-51p., http://www.centexbel.be/files/publication-pdf/ MTE_Buyle.pdf

[70] Karahan, H.A., Özdoğan, E., Demir, A., Ayhan, H. and Seventekin, N., 2009, Effects of Atmospheric Pressure Plasma Treatments on Certain Properties of Cotton Fabrics, Fibers \& Textiles in Eastern Europe, 17 (2), 19-22p.

[71] Karahan, A., Yaman, N., Demir, A., Ozdoğan, E., Oktem, T. and Seventekin, S., 2006, Tekstilde Plazma Teknolojisinin Kullanım Olanakları: Plazma Nedir?, Tekstil ve Konfeksiyon, 16(1),302-309p.

[72] Jocic, D., Vilchez, S., Topalovic, T., Molina, R., Navarro, A., Jovancic, P., Julia, M.R. and Erra, P., 2005, Effect of Low-Temperature Plasma and Chitosan Treatment on Wool Dyeing with Acid Red 27, Journal of Applied Polymer Science, 97(6), 2204-2214p.

[73] http://www.tno.nl/downloads/def_maritiem_plasmaapplicaties_DV2_05d046.pdf, 2012

[74] Ahmed, A., 2007, A Review of Plasma Treatment for Application on Textile Substrate, BSc. Thesis, The Faculty of Textile Science

[75] Erra, P., Molina, R., Jocic, D., Julia, M.R., Cuesta, A., and Tascon, J.M.D., 1999, Shrinkage Properties of Wool Treated with Low Temperature Plasma and Chitosan Biopolymer, Textile Research Journal, 69(11), 811-815p.

[76] Höcker, H., 2002, Plasma Treatment of Textile Fibers, Pure Appl. Chem., 74(3), 423-427p. 
[77] Wakida, T., Tokino, S., Niu, S., Lee, M., Uchiyama, H. and Kaneko, M., 1993, Dyeing Properties of Wool Treated with Low-Temperature Plasma Under Atmospheric Pressure, Textile Research Journal, 63(8), 438-442p.

[78] Yoon, N.M., Lim, Y.J., Tahara, M. and Takagishi, T., 1996, Mechanical and Dyeing Properties of Wool and Cotton Fabrics Treated with Low Temperature Plasma and Enzymes, Textile Research Journal, 66(5), 329-336p.

[79] Jing, Z., 1996, Silk Fabrics Modification Through Plasma Graft Copolymerization, Journal of Textile Research, 4

[80] Wakida, T., Lee, M., Sato, Y., Ogasawara, S., Ge, Y. and Niu, S., 1996, Dyeing Properties of Oxygen Low-Temperature Plasma-Treated Wool and Nylon 6 Fibers with Acid And Basic Dyes, Journal of the Society of Dyers and Colorists, 112(9), 233-236p.

[81] Wakida, T., Cho, S., Choi, S., Tokino, S. and Lee, M., 1998, Effect of Low Temperature Plasma Treatment on Color of Wool and Nylon 6 Fabrics Dyed with Natural Dyes, Textile Research Journal, 68(11), 848-853p.

[82] Kan, C.W., Chan, K., Yuen, C.W.M. and Miao, M.H., 1998, Surface Properties of LowTemperature Plasma Treated Wool Fabrics, Journal of Materials Processing Technology, 83(1-3), 180-184p.

[83] Kan, C.W., Chan, K., Yuen, C.W.M. and Miao, M.H., 1998, The Effect of Low-Temperature Plasma on The Chrome Dyeing of Wool Fiber, Journal of Materials Processing Technology, 82(1-3), 122-126p.

[84] Kan, C.W., Chan, K., Yuen, C.W.M. and Miao, M.H., 1999, Low Temperature Plasma on Wool Substrates: The Effect of The Nature of The Gas, Textile Research Journal, 69(6), 407-416p.

[85] Kan, C.W., Chan, K. and Yuen, C.W.M., 2004, Surface Characterization of Low Temperature Plasma Treated Wool Fiber-The Effect of The Nature of Gas-, Fibers and Polymers, 5(1), 52-58p.

[86] Iriyama, Y., Mochizuki, T., Watanabe, M. and Utada, M., 2002, Plasma Treatment of Silk Fabrics for Better Dyeability, Journal of Photopolymer Science and Technology, 15(2), 299-306p.

[87] Sun, D. and Stylios, G.K., 2004, Effect of Low Temperature Plasma Treatment on The Scouring and Dyeing of Natural Fabrics, Textile Research Journal, 74(99), 751-756p.

[88] Biniaś, D., Włochowicz, A. and Binias, W., 2004, Selected Properties of Wool Treated By Low-Temperature Plasma, Fibers\&Textiles in Eastern Europe, 12(2), 58-62p.

[89] Sun, D. and Stylios, G.K., 2005, Investigating The Plasma Modification of Natural Fiber Fabrics-The Effect on Fabric Surface and Mechanical Properties, Textile Research Journal, 75(9), 639-644p.

[90] Masukuni, M. and Norihiro, I., 2006, Dyeing Properties of Argon-Plasma Treated Wool, Sen'I Gakkaishi, 62(9), 205-211p. 
[91] Kan, C. and Yuen, C.M., 2006, Dyeing Behavior of Low Temperature Plasma Treated Wool, Plasma Processes and Polymers, 3 (8), 627-635p.

[92] El-Zawahry, M.M., Ibrahim, N.A. and Eid, M.A., 2006, The Impact of Nitrogen Plasma Treatment upon the Physical-Chemical and Dyeing Properties of Wool Fabric, Polymer-Plastics Technology and Engineering, 45(10), 1123-1132p.

[93] Demir, A., Karahan, A., Ozdogan, E., Oktem, T. and Seventekin, N., 2008, The Synergetic Effects of Alternative Methods in Wool Finishing, Fibers\&Textiles in Eastern Europe, 16(2), 89-94p.

[94] Chvalinova, R. and Wiener, 2008, Sorption Properties of Wool Fibers After Plasma Treatment, II Central European Symposium on Plasma Chemistry, Chem. Listy 102, 1473-1477p.

[95] Naebe, M., Cookson, P. G., Rippon, J., Brady, R. P., Wang, X., Brack, N. and van Riessen, G., 2010, Effects of Plasma Treatment of Wool on the Uptake of Sulfonated Dyes with Different Hydrophobic Properties, Textile Research Journal, 80(4), 312-324p.

[96] Demir A., 2010, Atmospheric Plasma Advantages for Mohair Fibers in Textile Applications, Fibers and Polymers, 11(4), 580-585p.

[97] Atav, R. and Yurdakul, A., 2011, Low Temperature Dyeing of Plasma Treated Luxury Fibers. Part I: Results for Mohair (Angora Goat), Fibers \& Textiles in Eastern Europe, 19(2), 84-89p.

[98] http://en.wikipedia.org/wiki/Gamma_ray, 2012

[99] http://web.princeton.edu/sites/ehs/osradtraining/radiationproperties/radiationproperties.htm, 2012

[100] Zohdy, M.H., El-Naggar, A.M. and Marie, M.M., 1999, Effect of Copper Treatment on The Dyeability of Gamma Irradiated Acrylic Fabrics with Different Dyestuffs, Materials Chemistry and Physics, 61, 237-243p.

[101] Aytac, A., Sen, M., Deniz, V. and Guven, O., 2007, Effect of Gamma Irradiation on The Properties of Tyre Cords, Nuclear Instruments and Methods in Physics Research, 265, 271-275p.

[102] Zohdy, M.H., El-Naggar, A.M. and Abdallah, W.A., 1997, Silk Screen Printing of Some Reactive Dyes on Gamma Irradiated Wool Fabrics, Polymer Degradation and Stability, 55, 185-189p.

[103] Horio, M., Ogami, K., Kondo, T. and Sekimoto, K., 1962, Effect of Gamma Irradiation upon Wool Fibers, http://repository.kulib.kyoto-u.ac.jp/dspace/bitstream/ 2433/75949/1/chd041_1_001.pdf

[104] Beevers, R.B. and McLaren, K.G., 1974, The Effect of Low Doses of Co60 Gamma Radiation on Some Physical Properties and The Structure of Wool Fibers, Textile Research Journal, 44(12), 986-994p. 
[105] Millington, K.R., 2000, Comparison of The Effects of Gamma and Ultraviolet Radiation on Wool Keratin, Journal of The Society of Dyers and Colourists, 116, 266-272p.

[106] Kan, C.W., 2008, Impact on Textile Properties of Polyester with Laser, Optics \& Laser Technology, 40, 113-119p.

[107] http://en.wikipedia.org/wiki/Laser, 2012

[108] ttp://resources.alibaba.com/topic/800007870/Laser_processing_technology_in_Textile_and_Apparel.htm, 2012

[109] Montazer, M., Taheri, S.J. and Harifi, T., 2011, Effect of Laser CO2 Irradiation on Various Properties of Polyester Fabric: Focus on Dyeing, Journal of Applied Polymer Science, 124(1), 342-348p.

[110] Esteves, F. and Alonso, H., 2007, Effect of CO2 Laser Radiation on Surface and Dyeing Properties of Synthetic Fibers, Research Journal of Textile and Apparel, 11(3), 42-47p.

[111] http://en.wikipedia.org/wiki/Excimer_laser, 2012

[112] Knittel, D. and Schollmeyer, E., 1998, Surface Structuring of Synthetic Fibers by UV Laser Irradiation. Part III. Surface Functionality Changes Resulting from Excimer-Laser Irradiation, Polymer International, 45, 103-109p.

[113] Nourbakhsh, S. and Ebrahimi, I., 2012, Different Surface Modification of Poly (Ethylene Terephthalate) and Polyamide 66 Fibers by Atmospheric Air Plasma Discharge and Laser Treatment: Surface Morphology and Soil Release Behavior, Journal of Textile Science\&Engineering, 2(2), http://dx.doi.org/10.4172/2165-8064.1000109

[114] Bahtiyari, M.I., 2011, Laser Modification of Polyamide Fabrics, Optics \& Laser Technology, 43(1), 114-118p.

[115] Yip, J., Chan, K., Sin, K. and Lau, K., 2002, UV Excimer Laser Modification on Polyamide Materials: Effect on The Dyeing Properties, Materials Research Innovations, 6(2), 73-78p.

[116] Buyukakınc1, B.Y., 2012, Usage of Microwave Energy in Turkish Textile Production Sector, Energy Procedia, 14, 424-431p.

[117] http://en.wikipedia.org/wiki/Microwave, 2012

[118] http://www.gallawa.com/microtech/mwave.html, 2012

[119] http://www.microwavetec.com/theor_basics.php, 2012

[120] Ahmed, N.S.E and El-Shishtawy, R.M., 2010, The Use of New Technologies in Coloration of Textile Fibers, Journal of Material Science, 45(5), 1143-1153p.

[121] http://www.rsc.org/images/evaluserve_tcm18-16758.pdf, 2012

[122] Collins, J.M. and Leadbeater, N.E., 2007, Microwave Energy: A Versatile Tool for The Biosciences, Organic \& Bimolecular Chemistry, 5, 1141-1150p. 
[123] Haggag, K., Hanna, H.L., Youssef, B.M. and El-Shimy, N.S., March 1995, Dyeing Polyester With Microwave Heating Using Disperse Dyestuffs, American Dyestuff Reporter, 22-35p.

[124] Delaney, M.J. and Seltzer, I., 1972, Microwave Heating for Fixation of Pad-dyeings on Wool, Journal of the Society of Dyers and Colorists, 88(2), 55-59p.

[125] Zhao, X. and He, J.X., 2011, Improvement in Dyeability of Wool Fabric By Microwave Treatment, Indian Journal of Fiber \& Textile Research, 36(1), 58-62p.

[126] Leeder, J.D. , McGregor, B.A. and Steadman, R.G., 1998, Properties and Performance of Goat Fiber, RIRDC Publication, No 98/22, RIRDC, Proje No: ULA-8A

[127] Machi, S., 1996, New Trends of Radiation Processing Applications, Radiation Physics and Chemistry, 47(3), 333-336p.

[128] Li, J., Huang, Y., Xu, Z. and Wang, Z., 2005, High-Energy Radiation Technique Treat on The Surface Of Carbon Fiber, Materials Chemistry and Physics, 94, 315-321p.

[129] Alberti, A., Bertini, S., Gastaldi, G., Iannaccone, N., Macciantelli, D., Torri, G. and Vismara, E., 2005, Electron Beam Irradiated Textile Cellulose Fibers. ESR Studies and Derivatisation with Glycidyl Methacrylate (GMA), European Polymer Journal, 41, 1787-1797p.

[130] Fatarella, E., Ciabatti, I. and Cortez, J., 2010, Plasma and Electron-Beam Processes as Pretreatments for Enzymatic Processes, Enzyme and Microbial Technology, 46, 100-106p.

[131] Vahdat, A., Bahrami, H., Ansari, N. and Ziaie, F., 2007, Radiation Grafting of Styrene onto Polypropylene Fibers by A 10mev Electron Beam, Radiation Physics and Chemistry, 76, 787-793p.

[132] Clough, R.L., 2001, High-Energy Radiation and Polymers: A Review of Commercial Process and Emerging Applications, Nuclear Instruments and Methods in Physics Research B, 185, 8-33p.

[133] Chmielewski, A.G. and Haji-Saeid, M., 2004, Radiation Technologies: Past, Present and Future, Radiation Physics and Chemistry, 71, 16-20p.

[134] Oktem, T., Ozdogan, E., Namligoz, S.E., Oztarhan, A., Tek, Z., Tarakcioglu, I. and Karaaslan, A., 2006, Investigating the Applicability of Metal Ion Implantation Technique (MEVVA) to Textile Surfaces, Textile Research Journal, 76(1), 32-40p.

[135] Ion Beam Processing (IBP) Technologies, Sector Study, FINAL REPORT, Prepared for the North American Technology and Industrial Base Organization (NATIBO), Prepared by BDM Federal, June 1996

[136] Dong, H. and Bell, T., 1999, State-of-The-Art Overview: Ion Beam Surface Modification of Polymers Towards Improving Tribological Properties, Surface and Coatings Technology, 111, 29-40p. 
[137] Montero, G., Hinks, D. and Hooker, J., 2003, Reducing Problems of Cyclic Trimer Deposits in Supercritical Carbon Dioxide Polyester Dyeing Machinery, Journal of Supercritical Fluids, 26, 47-54p.

[138] Fernandez Cid, M.V., van Spronsen, J., van der Kraan, M., Veugelers, W.J.T., Woerlee, G.F. and Witkamp, G.J., 2007, A significant approach to dye cotton in supercritical carbon dioxide with fluorotriazine reactive dyes, J. of Supercritical Fluids, 40, 477-484p.

[139] Hou, A. and Dai, J., 2005, Kinetics of Dyeing of polyester with CI Disperse Blue 79 in Supercritical Carbondioxide, Coloration Technology, 121, 18-20p.

[140] Özcan, A.S., Clifford, A.A., Bartle, K.D. and Lewis, D.M., 1998, Dyeing of Cotton Fibres with Disperse Dyes in Supercritical Carbon Dioxide, Dyes and Pigments, 36 (2), 103-110p.

[141] New Technologies in Textile Dyeing and Finishing, http://www.industryhk.org/ english/fp/fp_hki/files/HKI_03_09_textile_e.pdf

[142] Özcan, A.S., and Özcan, A., 2005, Adsorption Behavior of A Disperse Dye on Polyester in Supercritical Carbon Dioxide, Journal of Supercritical Fluids, 35, 133-139p.

[143] Hou, A., Chen, B., Dai, J. and Zhang, K., 2010, Using Supercritical Carbon Dioxide as Solvent to Replace Water in Polyethylene Terephthalate (PET) Fabric Dyeing Procedures, Journal of Cleaner Production, 18,1009-1014p.

[144] Jun, J.H., Ueda, M., Sawada, K., Sugimotod, M. and Urakawaa, H., 2005, Supercritical Carbon Dioxide Containing A Cationic Perfluoropolyether Surfactant for Dyeing Wool, Coloration Technology, 121, 315-319p.

[145] Özcan, A.S., Clifford, A.A., Bartle, K.D., Broadbent, P.J. and Lewis, D.M., 1998, Dyeing of Modified Cotton Fibres with Disperse Dyes from Supercritical Carbon Dioxide, Journal of The Society of Dyers and Colourists, 114, 169-173p.

[146] Van der Kraan, M., Bayrak, Ö., Fernandez Cid, M.V., Woerlee, G.F., Veugelers, W.J.T. and Witkamp, G.J., Textile Dyeing in Supercritical Carbon Dioxide, http:// www.isasf.net/fileadmin/files/Docs/Versailles/Papers/PMt2.pdf

[147] Guzel, B. and Akgerman, A., 2000, Mordant Dyeing of Wool By Supercritical Processing, Journal of Supercritical Fluids, 18, 247-252p.

[148] Sawada, K., Takagi, T., Jun, J.H., Ueda, M. and Lewis, D.M., 2002, Dyeing Natural Fibres in Supercritical Carbon Dioxide Using A Nonionic Surfactant Reverse Micellar System, Coloration Technology, 118(5), 233-237p.

[149] Jun, J.H., Sawada K. and Ueda, M., 2004, Application of Perfluoropolyether Reverse Micelles in Supercritical CO2 to Dyeing Process, Dyes and Pigments, 61, 17-22p.

[150] Van der Kraan, M., Fernandez Cid, M.V., Woerlee, G.F., Veugelers, W.J.T. and Witkamp, G.J., 2007, Dyeing of Natural and Synthetic Textiles in Supercritical Carbon Dioxide with Disperse Reactive Dyes, The Journal of Supercritical Fluids, 40, 470-476p. 
